\title{
The effects of moisture on the dielectric relaxation of urethane dimethacrylate polymer and composites
}

\author{
N. M. MOHSEN*, R. G. CRAIG ${ }^{\dagger} \&$ F. E. FILISKO ${ }^{\ddagger}{ }^{*}$ Sheffield Pharmaceuticals Inc., Ann Arbor, ${ }^{\dagger}$ School of \\ Dentistry and ${ }^{\ddagger}$ Department of Materials Science and Engineering, University of Michigan, Ann Arbor, U.S.A.
}

SUMMARY Dielectric characterization evaluated the influence of sorbed moisture on urethane dimethacrylate (UDMA) polymer matrix and unsilanated and silanated zirconia-silica (ZS)-filled UDMA composites. The moisture content (MC) of samples tested ranged from 0 to $7 \cdot 32 \%$ with maximum values for UDMA, silanated and unsilanated ZSfilled UDMA were $3 \cdot 72,6 \cdot 0$ and $7 \cdot 32 \%$, respectively. Dielectric spectra were measured from 0.053 to $100 \mathrm{kHz}$ and from -180 to $180^{\circ} \mathrm{C}$. Small MC stiffened the polymers, which was shown by a shift of $\beta$-peaks to higher temperatures, a decrease in the half width of bands and an increase in the change of activation energies. Higher MC resulted in water plasticizing the polymer by shifting the $\beta$-peaks to lower temperatures. Maximum water sorption restricted the motion of the polymer chains and the $\beta$-peaks shifted to higher temperatures. Further, increasing MC shifted the $\alpha$-relaxation to lower temperatures in both UDMA and composites. However, in composites with unsilanated $\mathrm{ZS}$, a new relaxation occurred at high temperatures and low frequencies which was attributed to Maxwell-Wagner-Sillars (MWS) polarization. Thus, in UDMA, water occurs as fragments that form non-freezing clusters. However, in unsilanated ZS-UDMA composites, bulk water can exist at the polymer-filler interface and form disordered structures of ice at low temperatures which can evaporate at high temperatures. Silanated ZS-UDMA composites function similarly to UDMA at low MC but are more plasticized at high temperatures.

KEYWORDS: dielectric interfacial characterization, Maxwell-Wagner-Sillars polarization and/or interfacial polarization, moisture effect on composites containing silanated filler, moisture effect on composites containing untreated filler, moisture effect on UDMA

\section{Introduction}

Synthetic polymers are extensively used in the biological environment and thus there is considerable concern about the nature of the interaction between the water in such environment and the polymer. For successful performance of polymers in these environments, it is of great interest to understand the changes in the molecular dynamics of the polymer in the presence of water and in the states of the water molecules.

Water in polymers consists of bound and bulk water, bound water being that portion that interacts so strongly with polymers it becomes associated with it, while bulk water is the portion that is not associated with or bound to the polymer (Deodhar, 1980). The bound water readily supercools without crystallization, while the bulk water crystallizes to ice (Pathmanathan \& Johari, 1991).

Water interaction with bulk polymers was first described by Starkweather (1980) in Nylon 66 as being tightly bound, non-freezing and uniformly distributed. When water is first absorbed into the polymer, water molecules are believed to hydrogen bond between two amides groups, acting as crosslinks at low temperatures but plasticizing at elevated temperatures because of greater thermal mobility of water compared with segments of the polymer chains. 
Water molecules were also found by Brown (1980) to hydrogen bond to esters and carboxyl groups in amorphous acrylic polymers; however, above a characteristic level of water for each kind of polymer, the water appears in a second form generally called 'clusters'. These clusters consist of an average of three molecules bonded at polar sites (Starkweather, 1980) or as a separate phase of water in a less polar polymer (Johnson et al., 1980).

Early investigations of the effect of water on dielectric low temperature relaxations of polyamides by Boyd (1959), polyurethanes by McCrum et al. (1967) and polycarbonate by Johnson et al. (1980) were shown to enhance the height of these relaxations by the presence of unassociated non-freezing water. In addition, a secondary dielectric loss peak associated with frozen clustered water occurred in polycarbonate about $40{ }^{\circ} \mathrm{C}$ below its $\beta$-relaxation. Further, liquid clustered water at $23{ }^{\circ} \mathrm{C}$ yielded a loss mechanism in the $\mathrm{MHz}$ region in polyethylene and in the $\mathrm{kHz}$ region for polycarbonate that was interpreted as a Maxwell-Wagner-Sillars (MWS) polarization. Such an effect is because of the existence of free charges in solid material at the interface that develop from the presence of water inclusion.

The MWS polarization, which is also known as interfacial polarization arises from the accumulation of charges at the interface between two phases whose conductivities and permittivities differ as described by Hanai (1960), Hedvig (1977) and Smyth (1955). The occurrence of the MWS peak depends on the permittivity of the inclusion. If the inclusion has a low permittivity $\left(\varepsilon^{\prime}=1-5\right)$, the relaxation will appear at low frequencies $\left(f_{\mathrm{m}}=10^{-2} \mathrm{~Hz}\right)$ and may only appear as a steeply increasing conductivity in alternating current (AC) measurements. As the permittivity of the inclusions increases, so does the frequency of the relaxation and with water $\left(\varepsilon^{\prime}=76.8\right)$ it may occur up to $100 \mathrm{kHz}$, and a characteristic peak may develop (Smyth, 1955; Vanbeek 1967; Hedvig, 1977).

This investigation examines the effect of moisture sorption on the molecular dynamics of a urethane dimethacrylate (UDMA) polymer by dielectric measurements in order to understand the behaviour of water-polymer interaction. In addition, the effect of moisture on a UDMA composite containing untreated and silanated filler was investigated to elucidate the effect of moisture on the stability of the interface.

\section{Method and materials}

\section{Composite system}

The specifications of the polymer and filler systems used, as well as the procedures for filler silanation and composites formulation followed, were described by Mohsen et al. (2000).

\section{Sample conditioning}

Samples were dried in vacuum at $100{ }^{\circ} \mathrm{C}$ for $72 \mathrm{~h}$ to remove the moisture. Sorption of water vapour was carried out by exposing the samples over vapours of distilled water until they were conditioned to equilibrium and no more moisture could be sorbed. Moisture sorption by the unfilled-UDMA was lower than the sorption of the ziroconia-silica (ZS)-filled UDMA, which was higher than the sorption of the silanated ZS-filled UDMA. Moisture content (MC) was defined as grams of sorbed moisture per $1 \mathrm{~g}$ of dried polymer. The maximum moisture sorption attained by the UDMA was $3.72 \mathrm{wt} \%$, and 7.32 and $6.0 \mathrm{wt} \%$ for unsilanated ZS-filled UDMA and 3-methacryloxypropyltrimethoxysilane (MAPM)-silanated ZS-filled UDMA, respectively.

\section{Dielectric measurements}

The dielectric apparatus and experimental conditions were described in a study by Mohsen et al. (1999). The dielectric loss tangent $\left(\tan (\delta)_{\varepsilon}\right)$ and capacitance $(C)$ measurements were carried out over a frequency range of $0.015-100 \mathrm{kHz}$ from -180 to $180{ }^{\circ} \mathrm{C}$. In addition, the $\tan (\delta)_{\varepsilon}$ and capacitance $\left(C_{\mathrm{o}}\right)$ were measured for an empty cell with the same experimental conditions and sample thickness over the frequency range at ambient temperature.

\section{Results}

The effect of moisture on the dielectric behaviour of UDMA

The $\tan (\delta)_{\varepsilon}$ for the UDMA with MC of $0,0 \cdot 69,1 \cdot 0,1 \cdot 83$, 3.0 and $3.72 \mathrm{wt} \%$ measured at $1.0 \mathrm{kHz}$ are plotted against temperature in Fig. 1. The $\tan (\delta)_{\varepsilon}$ curves show a sub- $T_{\mathrm{g}}$ or $\beta$-relaxation peak, an $\alpha$-relaxation peak and a substantial increase in the values of $\tan (\delta)_{\varepsilon}$ at high temperatures with $\mathrm{MC}>1.83 \mathrm{wt} \%$. The curves also show the obstruction of the $\alpha$-relaxation by a new peak 


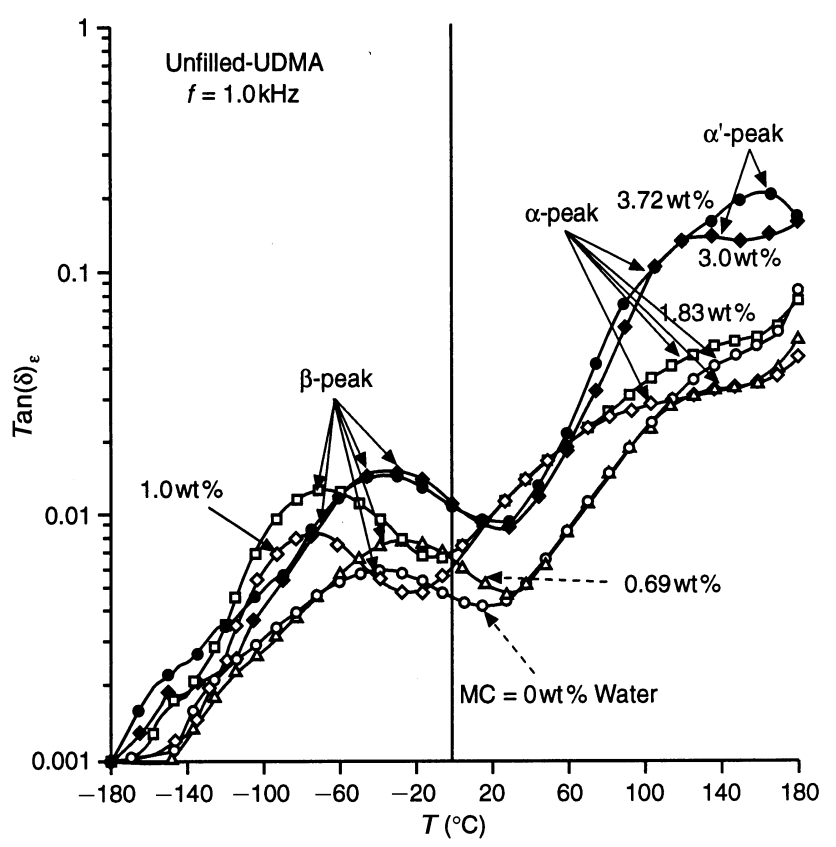

Fig. 1. Tan $(\delta)$, against temperature measured at $1.0 \mathrm{kHz}$ for UDMA with MC of $0,0.69,1 \cdot 0,1 \cdot 83,3.0$ and $3.72 \mathrm{wt} \%$.

$\left(\alpha^{\prime}\right)$ that appeared as a shoulder at $100{ }^{\circ} \mathrm{C}$ with MC $\geq 1.83$ wt $\%$. The maximum temperatures of the $\alpha$ - and $\beta$-peaks obtained from the $\tan (\delta)_{\varepsilon}$ curves measured at different frequencies are shown in Table 1. These data show the $\alpha$-relaxation is shifted to slightly lower temperatures at very high MC ( $\geq 3.0 \mathrm{wt} \%)$. The $\beta$-relaxation shifted to slightly higher temperatures with MC at 0.69 wt \%, shifted back to lower temperatures with $\mathrm{MC}>0.69 \mathrm{wt} \%$ and finally, to higher values with $\mathrm{MC}=1.83 \mathrm{wt} \%$.

Table 1. Maximum peaks temperatures $\left({ }^{\circ} \mathrm{C}\right)$ from $\tan (\delta)_{\varepsilon}$ measurements for different amount of MC in UDMA polymer for $\alpha$-relaxations at $5.5,10.0$ and $33.3 \mathrm{kHz}$ and for $\beta$-relaxations at $0 \cdot 252,1 \cdot 0$ and $10 \cdot 0 \mathrm{kHz}$

\begin{tabular}{|c|c|c|c|c|c|c|}
\hline \multirow[b]{3}{*}{ MC wt \% } & \multicolumn{6}{|c|}{ Maximum peaks temperature $\left({ }^{\circ} \mathrm{C}\right)$} \\
\hline & \multicolumn{3}{|c|}{$\alpha$-Relaxation $(\mathrm{kHz})$} & \multicolumn{3}{|c|}{$\beta$-Relaxation $(\mathrm{kHz})$} \\
\hline & $5 \cdot 5$ & $10 \cdot 0$ & $33 \cdot 3$ & $0 \cdot 252$ & $1 \cdot 0$ & $10 \cdot 0$ \\
\hline $0 \cdot 0$ & $156 \cdot 4$ & $158 \cdot 2$ & $168 \cdot 5$ & $-58 \cdot 2$ & $-38 \cdot 8$ & $0 \cdot 4$ \\
\hline 0.69 & $152 \cdot 4$ & $157 \cdot 4$ & $172 \cdot 2$ & $-36 \cdot 1$ & $-25 \cdot 5$ & $6 \cdot 4$ \\
\hline $1 \cdot 00$ & $157 \cdot 4$ & $160 \cdot 6$ & $171 \cdot 1$ & $-81 \cdot 8$ & $-74 \cdot 2$ & $-51 \cdot 5$ \\
\hline $1 \cdot 83$ & $154 \cdot 8$ & $159 \cdot 8$ & - & $-79 \cdot 8$ & $-66 \cdot 7$ & $-42 \cdot 4$ \\
\hline $3 \cdot 00$ & $136 \cdot 5$ & - & - & $-45 \cdot 3$ & $-32 \cdot 5$ & $-3 \cdot 5$ \\
\hline $3 \cdot 72$ & - & - & - & $-50 \cdot 0$ & $-40 \cdot 0$ & $-4 \cdot 9$ \\
\hline
\end{tabular}
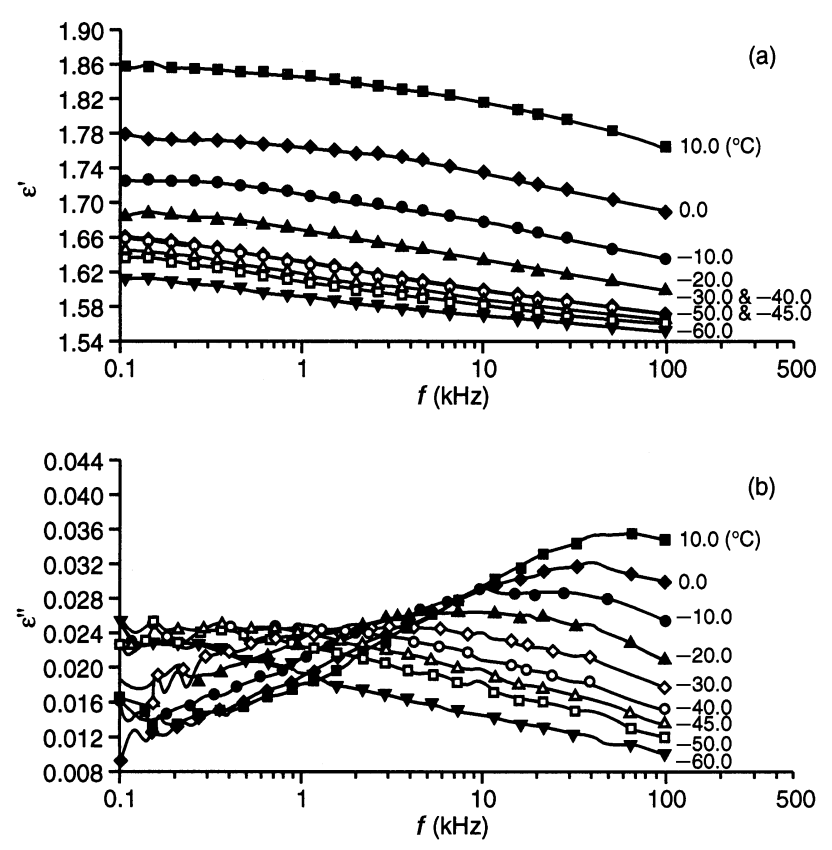

Fig. 2. The frequency dependence of (a) $E^{\prime}$ and (b) $E^{\prime \prime}$ calculated over the temperature range of -60 to $10{ }^{\circ} \mathrm{C}$ for $\beta$-relaxation of UDMA polymer with MC of $3.72 \mathrm{wt} \%$.

The isothermal spectra of the dielectric permittivity $\varepsilon^{\prime}$ and the loss $\varepsilon^{\prime \prime}$ calculated using the formulations given by McCrum et al. (1967) at several temperatures for the $\beta$-relaxation for UDMA with MC of $3.72 \mathrm{wt} \%$ shown in Fig. 2, shows the persistence of the sub- $T_{\mathrm{g}}$ segmental mobility of the UDMA which was assigned to the mobility of the free amide groups according to Mohsen et al. (2000). The feature of this relaxation is similar to those of the local mode motions in polymers and molecular glasses noted by Pathmanathan and Johari (1991), namely, that there is an increase in the height of the $\varepsilon^{\prime \prime}$ peak with increasing temperature, a decrease in the half-width and an Arrhenius dependence of the rate on temperature with relatively low activation energy (Table 2). Such an increase in the height of $\varepsilon^{\prime \prime}$ decreased with an increase in the MC in UDMA. For instance, for vacuum-dried UDMA, the height of $\varepsilon^{\prime \prime}$ peak increased by $74 \%$ over the temperature range of $-60-10{ }^{\circ} \mathrm{C}$, while it increased by 46 and $40 \%$ with MC of 0.69 and $3.72 \mathrm{wt} \%$, respectively, in the same temperature range. The dielectric strength also increased with increasing MC and their values are presented in Table 3. In addition, the intensity $(\lambda)$ of $\varepsilon^{\prime \prime}$ and $\tan (\delta)_{\varepsilon}$-values also increased with increasing MC, while those of the half-width decreased. Both quantities are listed in Table 2. 
Table 2. Activation energies, intensities $(\lambda)$ of $\tan (\delta)_{\varepsilon}$ at $0.0252 \mathrm{kHz}$, half-widths of $\varepsilon^{\prime \prime}\left(\Delta_{1 / 2}\right)$ (decades) for $\alpha$-, $\alpha^{\prime}$ - and $\beta$-relaxations at 100,180 and $0{ }^{\circ} \mathrm{C}$, respectively, as a function of MC (wt \%) in UDMA polymer

\begin{tabular}{|c|c|c|c|c|c|c|c|c|}
\hline \multirow[b]{2}{*}{ MC wt \% } & \multicolumn{3}{|l|}{$\alpha$-Relaxation } & \multicolumn{2}{|l|}{$\alpha^{\prime}$-Relaxation } & \multicolumn{3}{|l|}{$\beta$-Relaxation } \\
\hline & $\Delta H(\mathrm{kcal} / \mathrm{mol})$ & $\lambda 0 \cdot 252(\mathrm{kHz})$ & $\Delta_{1 / 2} 100\left({ }^{\circ} \mathrm{C}\right)$ & $\Delta H(\mathrm{kcal} / \mathrm{mol})$ & $\Delta_{1 / 2} 180\left({ }^{\circ} \mathrm{C}\right)$ & $\Delta H(\mathrm{kcal} / \mathrm{mol})$ & $\lambda 0 \cdot 252(\mathrm{kHz})$ & $\Delta_{1 / 2} O\left({ }^{\circ} \mathrm{C}\right)$ \\
\hline $0 \cdot 0$ & $40 \cdot 4$ & $0 \cdot 016$ & $2 \cdot 94$ & $30 \cdot 9$ & $2 \cdot 13$ & $7 \cdot 5$ & $0 \cdot 0060$ & $4 \cdot 38$ \\
\hline $0 \cdot 69$ & $36 \cdot 4$ & $0 \cdot 024$ & $3 \cdot 14$ & $39 \cdot 5$ & $1 \cdot 34$ & $12 \cdot 2$ & $0 \cdot 0074$ & $3 \cdot 30$ \\
\hline $1 \cdot 00$ & $38 \cdot 6$ & $0 \cdot 022$ & $3 \cdot 82$ & $39 \cdot 5$ & - & $9 \cdot 2$ & 0.0074 & $3 \cdot 38^{*}$ \\
\hline $1 \cdot 83$ & $33 \cdot 9$ & $0 \cdot 027$ & - & $26 \cdot 9$ & $1 \cdot 87$ & $8 \cdot 9$ & 0.0118 & $3 \cdot 38^{+}$ \\
\hline $3 \cdot 00$ & $21 \cdot 3$ & - & - & $8 \cdot 0$ & $1 \cdot 26$ & $10 \cdot 6$ & $0 \cdot 0146$ & $3 \cdot 65$ \\
\hline $3 \cdot 72$ & $11 \cdot 6$ & - & - & $8 \cdot 2$ & $1 \cdot 26$ & $10 \cdot 6$ & 0.0146 & $3 \cdot 65$ \\
\hline
\end{tabular}

${ }^{*}$ Half-width at $-40{ }^{\circ} \mathrm{C} ;{ }^{\dagger} \Delta_{1 / 2}$ at $-40{ }^{\circ} \mathrm{C}$.

Table 3. Low $\left(\varepsilon_{0}\right)$ and high $\left(\varepsilon_{\infty}\right)$ frequency limiting values of $\varepsilon^{\prime}$ as well as dielectric increments $(\Delta \varepsilon)$ for $\alpha$ - and $\beta$-relaxations at 175 and $-30{ }^{\circ} \mathrm{C}$ as a function of MC (wt \%) in UDMA polymer

\begin{tabular}{|c|c|c|c|c|c|c|}
\hline \multirow[b]{2}{*}{ MC wt \% } & \multicolumn{3}{|c|}{$\alpha$-Relaxation } & \multicolumn{3}{|c|}{$\beta$-Relaxation } \\
\hline & $\varepsilon_{0}$ & $\varepsilon_{\infty}$ & $\Delta \varepsilon$ & $\varepsilon_{0}$ & $\varepsilon_{\infty}$ & $\Delta \varepsilon$ \\
\hline $0 \cdot 0$ & $3 \cdot 07$ & $2 \cdot 23$ & $0 \cdot 84$ & $1 \cdot 584$ & $1 \cdot 546$ & 0.038 \\
\hline $0 \cdot 69$ & $2 \cdot 67$ & $2 \cdot 20$ & $0 \cdot 47$ & $1 \cdot 571$ & $1 \cdot 527$ & $0 \cdot 044$ \\
\hline $1 \cdot 00$ & $2 \cdot 18$ & $1 \cdot 85$ & 0.33 & $1 \cdot 509$ & $1 \cdot 468$ & $0 \cdot 042$ \\
\hline $1 \cdot 83$ & $3 \cdot 17$ & $2 \cdot 37$ & $0 \cdot 80$ & 1.972 & $1 \cdot 885$ & $0 \cdot 087$ \\
\hline $3 \cdot 00 *$ & $70 \cdot 46$ & $2 \cdot 58$ & $67 \cdot 88$ & 1.944 & $1 \cdot 832$ & $0 \cdot 111$ \\
\hline $3 \cdot 72^{\dagger}$ & $130 \cdot 10$ & $2 \cdot 14$ & $127 \cdot 96$ & $1 \cdot 661$ & $1 \cdot 562$ & 0.093 \\
\hline
\end{tabular}

${ }^{*} \varepsilon_{0}, \varepsilon_{\infty}$ and $\Delta \varepsilon$ of $\alpha^{\prime}$-relaxation; ${ }^{\dagger} \varepsilon_{0}, \varepsilon_{\infty}$ and $\Delta \varepsilon$ of $\alpha^{\prime}$-relaxation.

Theoretically, the relaxed permittivity $\left(\varepsilon_{0}\right)$ is measured at $f=0 \mathrm{kHz}$, while the unrelaxed permittivity $\left(\varepsilon_{\infty}\right)$ is measured in the optical frequency range. Experimentally, such extremes were not attainable because of instrument limitations used. Therefore, in this research, what is referred to as $\varepsilon_{0}$ is actually $\varepsilon$ calculated at $f=0.01 \mathrm{kHz}$, i.e. $\varepsilon_{0}=\varepsilon_{0 \cdot 01}$. Similarly, $\varepsilon_{\infty}$ is $\varepsilon$ calculated at $f=200 \mathrm{kHz}$, i.e. $\varepsilon_{\infty}=\varepsilon_{200}$. The above holds true for all other variables calculated at such extreme frequencies, e.g. $M_{0}$ and $M_{\infty}$.

Because of the large contributions to $\varepsilon^{\prime \prime}$ from the DC conductivity at temperatures near glass transition temperature $\left(T_{\mathrm{g}}\right)$, the $\alpha$ - and $\alpha^{\prime}$-processes could not be observed. Therefore, the conductance and capacitance were converted into complex electrical modulus formalism according to Moynihan et al. (1973), where the real and imaginary components, $M^{\prime}$ and $M^{\prime \prime}$, were calculated at $175^{\circ} \mathrm{C}$, and the values are plotted in the low frequency range $(0.01-1 \mathrm{kHz})$ in Fig. 3 for the $\alpha^{\prime}$ relaxation of UDMA with MC of $0,0.69,1.83$ and $3.72 \mathrm{wt} \%$.
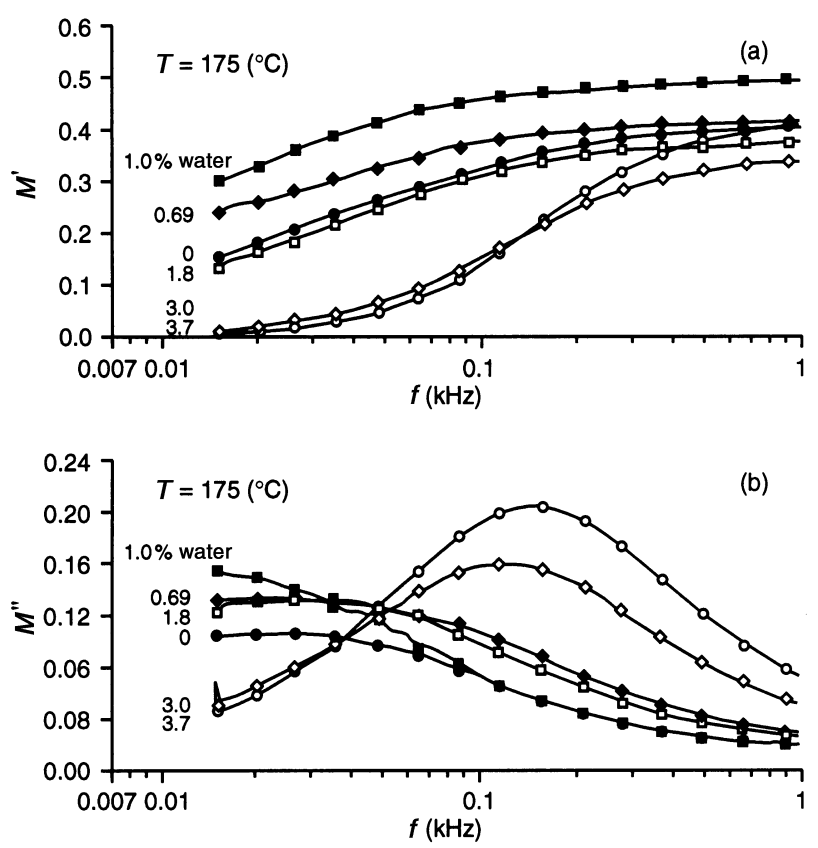

Fig. 3. The spectra of (a) $M^{\prime}$ and (b) $M^{\prime \prime}$ calculated over the frequency range of 0.01 to $1.0 \mathrm{kHz}$ and at $175^{\circ} \mathrm{C}$ for $\alpha^{\prime}$-relaxation of UDMA polymer with MC of $0,0.69,1 \cdot 0,1 \cdot 83,3.0$ and $3 \cdot 72$ wt $\%$.

The activation energies were calculated from the slopes and intercepts of the plots of the frequencies at which the maximum peaks of $\tan (\delta)_{\varepsilon}$ appeared against reciprocal temperature, while the half-widths of the bands $\left(\Delta_{1 / 2}\right)$ were calculated using the formalism given by McCrum et al. (1967) and the values are presented in Table 2. The $\Delta_{1 / 2}$-values for the $\alpha$-relaxation increased with increasing MC, while they decreased for the $\alpha^{\prime}$-relaxation until they approached a limiting value of $1 \cdot 26$ decades. 
The effect of moisture on the dielectric behaviour of unsilanated ZS-filled UDMA

The $\tan (\delta)_{\varepsilon}$ to $75 \mathrm{wt} \%$ unsilanated ZS-filled UDMA with MC of $0,2 \cdot 5,4 \cdot 0,6 \cdot 0$ and $7 \cdot 32 \mathrm{wt} \%$ measured at $0.020 \mathrm{kHz}$ are plotted against temperature in Fig. 4 . The $\tan (\delta)_{\varepsilon}$ curves show almost the same behaviour as those shown by the UDMA polymer, namely a sub- $T_{\mathrm{g}}$ or $\beta$-relaxation peak, an $\alpha$-relaxation peak, a substantial increase at high temperature because of proton transfer and an occurrence of a new peak $\left(\alpha^{\prime \prime}\right)$ with high MC. The maximum of the $\alpha$ - and $\beta$-peaks obtained from the $\tan (\delta)_{\varepsilon}$ curves measured at different frequencies are listed in Table 4. These data show the $\alpha$-relaxation is shifted to lower temperatures while its intensity increased. The curves also show that the $\beta$-relaxation is shifted to higher temperatures with $\mathrm{MC} \geq 2.5 \mathrm{wt} \%$ while it shifted back to lower temperatures with MC of $6.0 \mathrm{wt} \%$. Finally, the relaxation started to shift slightly to higher temperatures with $\mathrm{MC}>6.0 \mathrm{wt} \%$.

The isothermal curves for $M^{\prime}$ and $M^{\prime \prime}$ of the $\beta$-relaxation at several temperatures for the moistened UDMA composite with MC of 7.32 wt \% are shown in Fig. 5. Unlike the pure UDMA, the $\beta$-relaxation did not show the features of sub- $T_{\mathrm{g}}$ segmental mobility with moisture content $\geq 6.0 \mathrm{wt} \%$. For instance, the height of $M^{\prime \prime}$

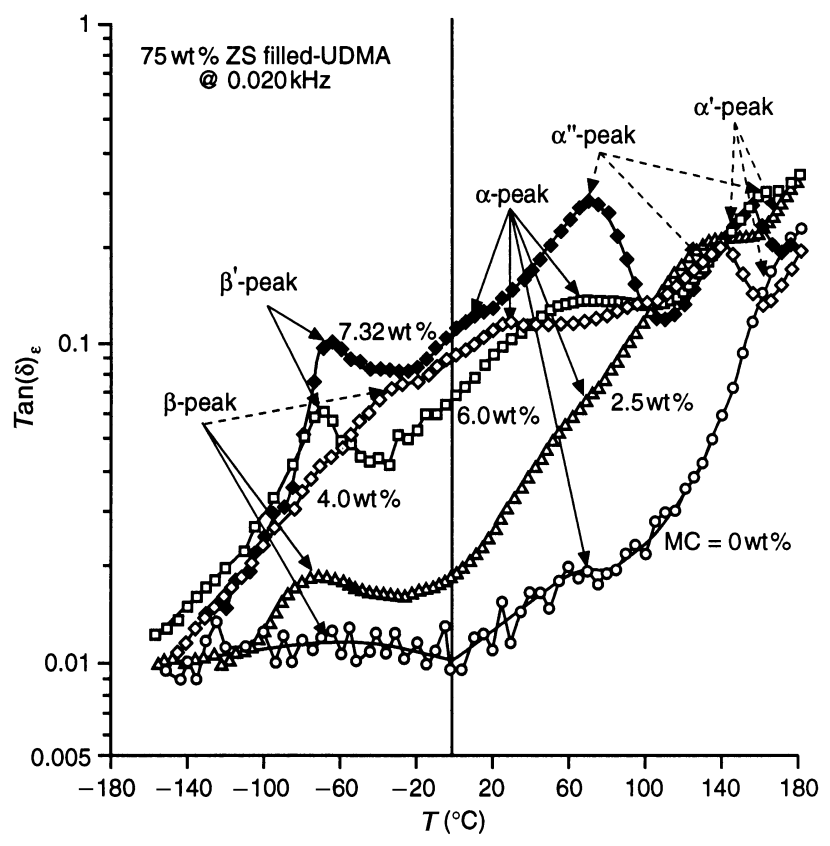

Fig. 4. Tan $(\delta)$, against temperature measured at $0 \cdot 020 \mathrm{kHz}$ for $75 \mathrm{wt} \% \mathrm{zs}$-filled UDMA polymer with MC of $0,2 \cdot 5,4 \cdot 0,6 \cdot 0$ and $7 \cdot 32$ wt $\%$.
Table 4. Maximum peaks temperature $\left({ }^{\circ} \mathrm{C}\right)$ from $\tan (\delta)_{\varepsilon}$ measurements for different MC in $75 \mathrm{wt} \%$ ZS-filled UDMA for $\alpha$-relaxations at $0.5,5.5$ and $10.0 \mathrm{kHz}$ and for $\beta$-relaxations at $0 \cdot 252,1 \cdot 0$ and $10 \cdot 0 \mathrm{kHz}$

\begin{tabular}{|c|c|c|c|c|c|c|}
\hline \multirow[b]{3}{*}{ MC wt $(\%)$} & \multicolumn{6}{|c|}{ Maximum peaks temperature $\left({ }^{\circ} \mathrm{C}\right)$} \\
\hline & \multicolumn{3}{|c|}{$\alpha$-Relaxation $(\mathrm{kHz})$} & \multicolumn{3}{|c|}{$\beta$-Relaxation $(\mathrm{kHz})$} \\
\hline & $0 \cdot 5$ & $5 \cdot 5$ & $10 \cdot 0$ & $0 \cdot 252$ & $1 \cdot 0$ & $10 \cdot 0$ \\
\hline $0 \cdot 0$ & - & $164 \cdot 9$ & $165 \cdot 9$ & $-69 \cdot 1$ & $-43 \cdot 3$ & - \\
\hline $2 \cdot 5$ & $122 \cdot 8$ & $140 \cdot 0$ & $155 \cdot 0$ & $-50 \cdot 0$ & $-40 \cdot 0$ & $10 \cdot 0$ \\
\hline $4 \cdot 0$ & - & - & - & $10 \cdot 0$ & $20 \cdot 0$ & - \\
\hline $6 \cdot 0$ & $115 \cdot 0$ & - & - & $-62 \cdot 5$ & $-55 \cdot 0$ & $-45 \cdot 0$ \\
\hline $7 \cdot 32$ & $70 \cdot 0$ & - & - & $-52 \cdot 5$ & $-45 \cdot 0$ & $-30 \cdot 0$ \\
\hline
\end{tabular}
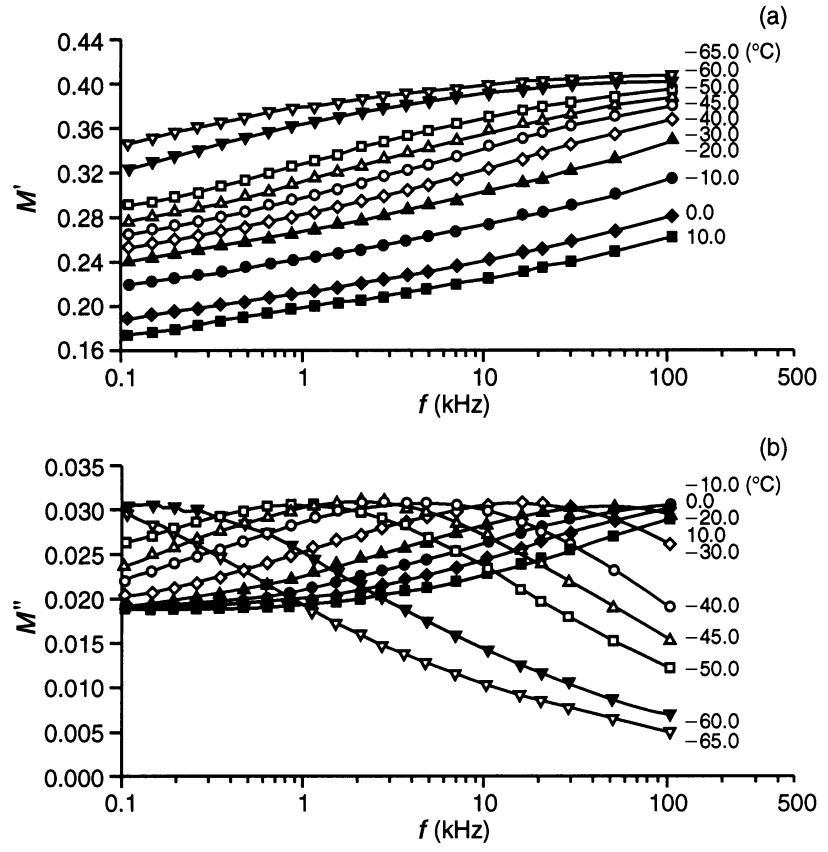

Fig. 5. The frequency dependence of (a) $M^{\prime}$ and (b) $M^{\prime \prime}$ calculated over the temperature range of -65 to $10{ }^{\circ} \mathrm{C}$ for $\beta^{\prime}$-relaxation of $75 \mathrm{wt} \%$ ZS-filled UDMA with MC of $7 \cdot 32 \mathrm{wt} \%$.

decreased only $4.4 \%$ over the temperature range of -60 to $0{ }^{\circ} \mathrm{C}$ with MC $7 \cdot 32 \mathrm{wt} \%$. To distinguish this peak from the regular sub- $T_{\mathrm{g}}$ peaks, this peak was named $\beta^{\prime}$ for the $75 \mathrm{wt} \%$ ZS-filled UDMA with MC $\geq 6 \cdot 0$.

The isothermal spectra of $M^{\prime}$ and $M^{\prime \prime}$ for the $\alpha^{\prime \prime}$-relaxation at several high temperatures for $75 \mathrm{wt} \%$ ZS-filled UDMA with MC of $7 \cdot 32 \mathrm{wt} \%$ are plotted in Fig. 6, which show the effect of the accumulation of the moisture at the interface, where it continues to disappear at higher temperatures. 

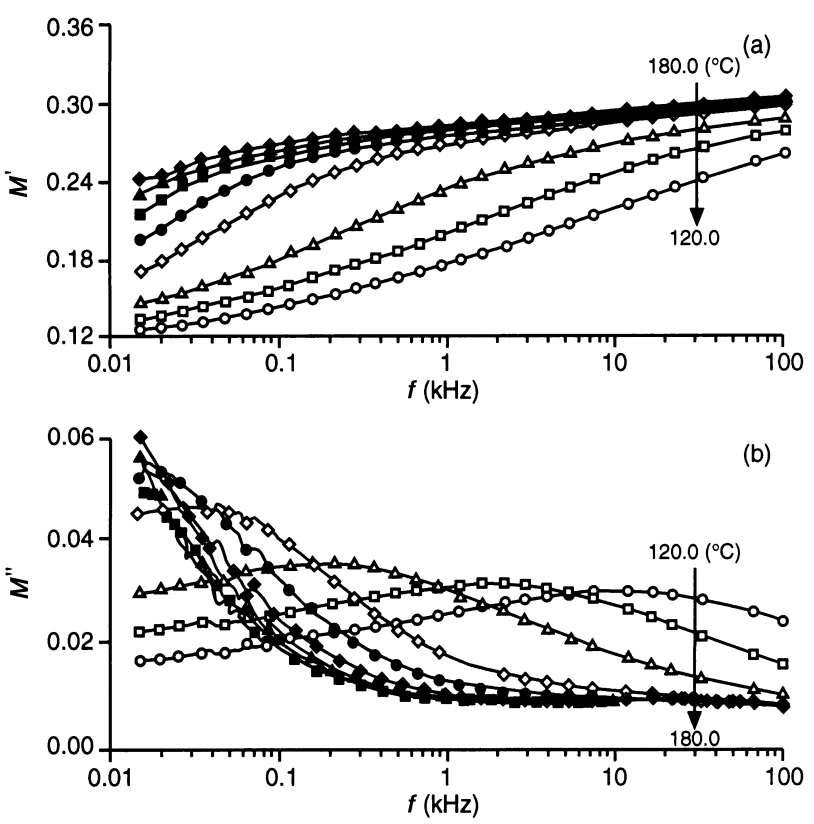

Fig. 6. The frequency dependence of (a) $M^{\prime}$ and (b) $M^{\prime \prime}$ calculated over the temperature range of $120-180{ }^{\circ} \mathrm{C}$ for $\alpha^{\prime \prime}$-relaxation of 75 wt \% ZS-filled UDMA with MC of $7 \cdot 32$ wt \%.

Table 5. Low $\left(\varepsilon_{0}\right)$ and high $\left(\varepsilon_{\infty}\right)$ frequency limiting values of $\varepsilon^{\prime}$ as well as dielectric increments $(\Delta \varepsilon)$ for $\alpha$ - and $\beta$-relaxations at 175 and $-30{ }^{\circ} \mathrm{C}$ as a function of $\mathrm{MC}(\mathrm{wt} \%)$ in $75 \mathrm{wt} \% \mathrm{ZS}$-filled UDMA

\begin{tabular}{lccccccc}
\hline & \multicolumn{3}{l}{$\alpha$-Relaxation } & & \multicolumn{3}{l}{$\beta$-Relaxation } \\
\cline { 2 - 3 } MC wt $\%$ & $\varepsilon_{0}$ & $\varepsilon_{\infty}$ & $\Delta \varepsilon$ & & $\varepsilon_{0}$ & $\varepsilon_{\infty}$ & $\Delta \varepsilon$ \\
\hline 0.0 & 3.033 & 2.715 & 0.318 & & 1.810 & 1.795 & 0.015 \\
2.5 & 3.744 & 3.219 & 0.525 & 2.431 & 2.361 & 0.071 \\
4.0 & 3.427 & 3.039 & 0.387 & 2.604 & 2.193 & 0.411 \\
6.0 & 3.767 & 3.242 & 0.525 & & 3.064 & 2.533 & 0.508 \\
7.32 & 3.738 & 3.278 & 0.460 & & 3.988 & 2.730 & 1.268 \\
\hline
\end{tabular}

The properties $\varepsilon_{\infty}, \varepsilon_{0}$ and dielectric increment of the dispersion $(\Delta \varepsilon)$ for $\beta$ - and $\alpha$-processes as a function of MC are presented in Table 5, while the values of the activation energies, $\lambda$ of $\tan (\delta)_{\varepsilon}$ and $\Delta_{1 / 2}$ are shown in listed in Table 6.

\section{The effect of moisture on the dielectric behaviour of MAPM-silanated ZS-filled UDMA}

The $\tan (\delta)_{\varepsilon}$ for $75 \mathrm{wt} \%$ MAPM-silanated ZS-filled UDMA with MC of $0,2 \cdot 5,4.0$ and $6.0 \mathrm{wt} \%$ measured at $0.053 \mathrm{kHz}$ are plotted against temperature in Fig. 7. The $\tan (\delta)_{\varepsilon}$ curves are similar to those shown by the UDMA polymer. The maximum of the $\alpha$ - and $\beta$-peaks obtained from the $\tan (\delta)_{\varepsilon}$ curves measured at different frequencies are shown in Table 7 . These data show shifts of the $\alpha$-relaxation peak maximum to lower temperatures and the $\beta$-relaxation showed similar trends of peaks shifts as those for the moistened UDMA.

The isothermal curves of $M^{\prime}$ and $M^{\prime \prime}$ for the moistened composite with MC of $6.0 \mathrm{wt} \%$ are plotted against frequency in Fig. 8 for the $\beta$-process and in Fig. 9 for the $\alpha^{\prime}$-process.

The properties $\varepsilon_{\infty}, \varepsilon_{0}$ and $\Delta \varepsilon$ for $\beta$ - and $\alpha$-processes as a function of MC are presented in Table 8 , while the values of apparent activity energy $(\Delta H), \lambda$ of $\tan (\delta)_{\varepsilon}$ and $\Delta_{1 / 2}$ as a function of MC are listed in Table 9.

\section{Discussion}

The effect of moisture on the dielectric behaviour of UDMA

The effect of moisture on the $\beta$-relaxation. At low amounts of MC, the first shift of the peak to higher temperatures indicates that the mobility of the free amide groups is suppressed as a result of the moisture sorption in the

Table 6. Activation energies, intensities $(\lambda)$ of $\tan (\delta)_{\varepsilon}$ at $0.0252 \mathrm{kHz}$, half-widths of $\varepsilon^{\prime \prime}\left(\Delta_{1 / 2}\right)$ (decades) for $\alpha$-, $\beta$ - and $\alpha^{\prime}$-relaxations at 165 , -45 and $135^{\circ} \mathrm{C}$, respectively, as a function of MC (wt \%) in 75 wt \% ZS-filled UDMA

\begin{tabular}{|c|c|c|c|c|c|c|c|}
\hline \multirow[b]{2}{*}{ MC wt \% } & \multicolumn{3}{|l|}{$\alpha$-Relaxation } & \multicolumn{3}{|l|}{$\beta$-Relaxation } & \multirow{2}{*}{$\frac{\alpha^{\prime} \text {-Relaxation }}{\Delta_{1 / 2} 135\left({ }^{\circ} \mathrm{C}\right)}$} \\
\hline & $\Delta H(\mathrm{kcal} / \mathrm{mol})$ & $\lambda 0 \cdot 252(\mathrm{kHz})$ & $\Delta_{1 / 2} 165\left({ }^{\circ} \mathrm{C}\right)$ & $\Delta H(\mathrm{kcal} / \mathrm{mol})$ & $\lambda 0.252(\mathrm{kHz})$ & $\Delta_{1 / 2}-45\left({ }^{\circ} \mathrm{C}\right)$ & \\
\hline $0 \cdot 0$ & $49 \cdot 9$ & 0.0146 & $4 \cdot 40^{*}$ & $6 \cdot 7$ & 0.0024 & $3 \cdot 10$ & $1 \cdot 47^{\dagger}$ \\
\hline $2 \cdot 5$ & $27 \cdot 4$ & 0.0625 & $3 \cdot 40$ & $6 \cdot 9$ & 0.0083 & $5 \cdot 11$ & $1 \cdot 61^{\ddagger}$ \\
\hline $4 \cdot 0$ & $16 \cdot 4$ & - & $3 \cdot 78$ & $15 \cdot 9$ & - & $6 \cdot 48^{\S}$ & $2 \cdot 74$ \\
\hline $6 \cdot 0$ & $21 \cdot 7$ & $0 \cdot 1413$ & $4 \cdot 72$ & $19 \cdot 6$ & 0.0514 & $4 \cdot 19^{\mathbb{I I}}$ & $3 \cdot 31$ \\
\hline $7 \cdot 32$ & $17 \cdot 4$ & $0 \cdot 1613$ & - & $17 \cdot 9$ & 0.0931 & $3 \cdot 31^{* *}$ & 3.56 \\
\hline
\end{tabular}

${ }^{*} \Delta_{1 / 2}$ for $\alpha$-peak at $140{ }^{\circ} \mathrm{C} ;{ }^{+} \Delta_{1 / 2}$ for $\alpha^{\prime}$-peak at $180{ }^{\circ} \mathrm{C} ;{ }^{\ddagger} \Delta_{1 / 2}$ for $\alpha^{\prime}$-peak at $180{ }^{\circ} \mathrm{C} ;{ }^{\S} \Delta_{1 / 2}$ for $\beta$-peak at $-10{ }^{\circ} \mathrm{C} ;{ }^{\mathbb{\pi}} \Delta_{1 / 2}$ for $\beta^{\prime}$-peak at $-45{ }^{\circ} \mathrm{C}$; $* * \Delta_{1 / 2}$ for $\beta^{\prime}$-peak at $-45^{\circ} \mathrm{C}$. 


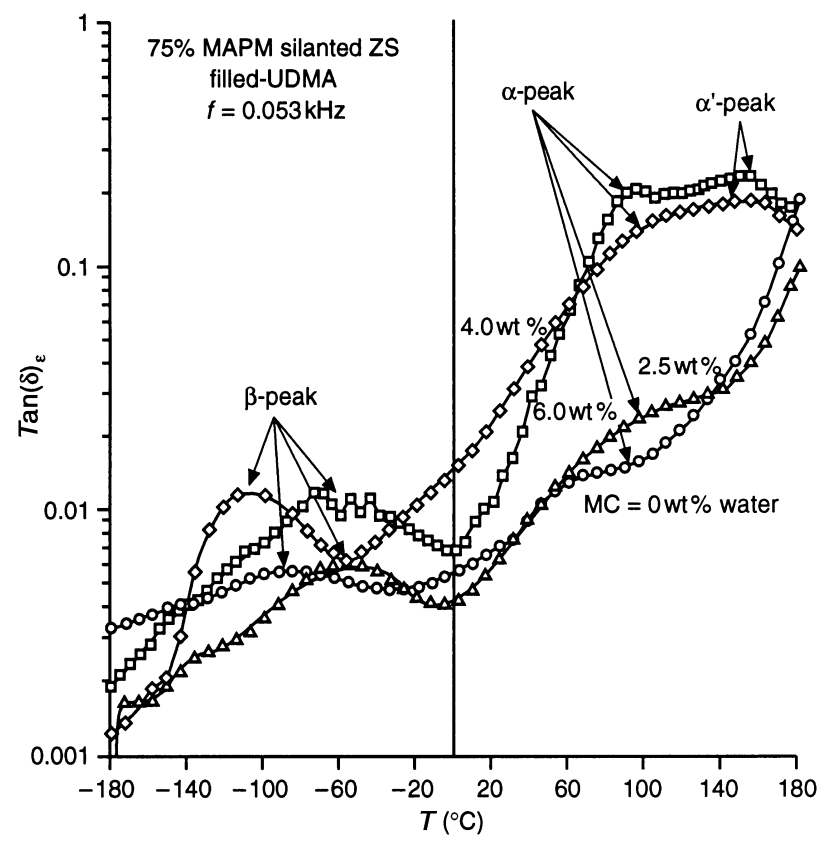

Fig. 7. $\operatorname{Tan}(\delta)$, against temperature measured at $0.053 \mathrm{kHz}$ for 75 wt \% MAPM silanated ZS-filled UDMA with MC of $0,25,4 \cdot 0$ and $6.0 \mathrm{wt} \%$.

Table 7. Maximum peaks temperature $\left({ }^{\circ} \mathrm{C}\right)$ from $\tan (\delta)_{\varepsilon}$ measurements for different MC in 75 wt \% MAPM-silanated ZS-filled UDMA for $\alpha$-relaxations at $5.5,10.0$ and $33.3 \mathrm{kHz}$ and for $\beta$-relaxations at $0.252,1 \cdot 0$ and $10 \cdot 0 \mathrm{kHz}$

\begin{tabular}{|c|c|c|c|c|c|c|}
\hline \multirow[b]{3}{*}{ MC wt $(\%)$} & \multicolumn{6}{|c|}{ Maximum peaks temperature $\left({ }^{\circ} \mathrm{C}\right)$} \\
\hline & \multicolumn{3}{|c|}{$\alpha$-Relaxation (kHz) } & \multicolumn{3}{|c|}{$\beta$-Relaxation $(\mathrm{kHz})$} \\
\hline & $5 \cdot 5$ & $10 \cdot 0$ & $33 \cdot 3$ & $0 \cdot 252$ & $1 \cdot 0$ & $10 \cdot 0$ \\
\hline $0 \cdot 0$ & - & $163 \cdot 8$ & $172 \cdot 9$ & $-39 \cdot 9$ & $-33 \cdot 0$ & - \\
\hline $2 \cdot 5$ & $150 \cdot 1$ & $156 \cdot 6$ & $173 \cdot 5$ & $-45 \cdot 7$ & $-31 \cdot 7$ & $-3 \cdot 8$ \\
\hline $4 \cdot 0$ & $135 \cdot 0$ & $138 \cdot 0$ & $143 \cdot 6$ & $-92 \cdot 5$ & $-90 \cdot 0$ & $-61 \cdot 9$ \\
\hline $6 \cdot 0$ & $129 \cdot 9$ & $131 \cdot 5$ & $134 \cdot 0$ & $-58 \cdot 9$ & $-49 \cdot 3$ & $-35 \cdot 9$ \\
\hline
\end{tabular}

lower range of $\leq 0.69 \mathrm{wt} \%$. Such suppression of the free amide groups in the polymer network implies that the water molecules increased the number of intermolecular bonds in the polymer as shown by Puffer and Sebenda (1967) by replacing the hydrogen bonds with water-amide hydrogen bonds demonstrated by Boyd (1959). A study of sorption and desorption isotherms of water in polyamides by Puffer and Sebenda (1967) has revealed that water molecules form an hydrogen bond between two CO groups (firmly bound water) and forms $\mathrm{H}$-bonds between the $\mathrm{CO}$ and the $\mathrm{NH}$ groups (loosely bound water). Another study by Rupley et al.

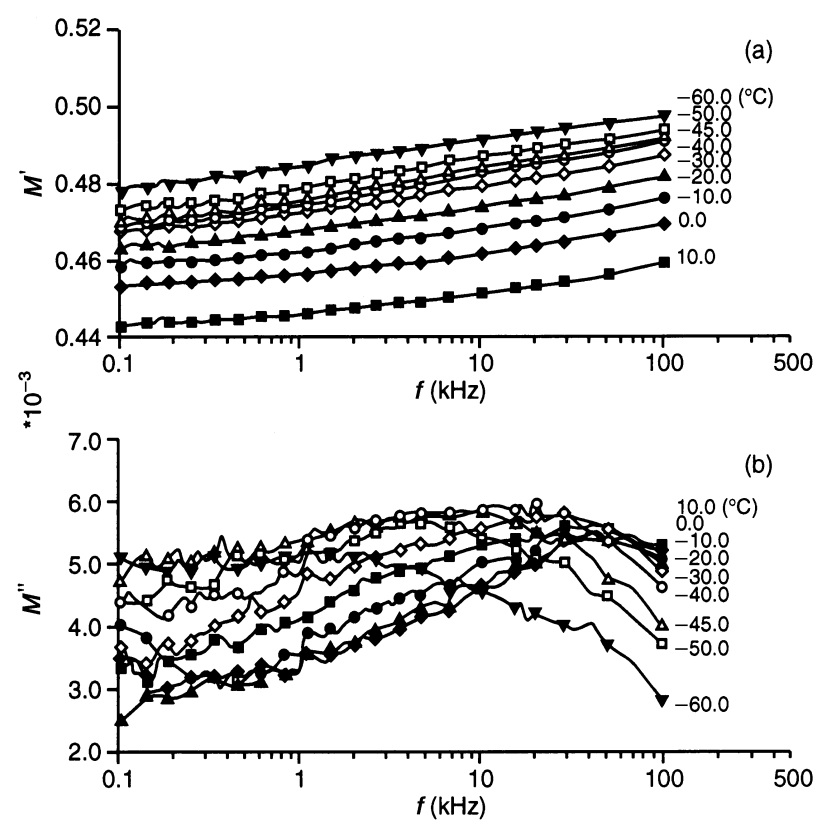

Fig. 8. The frequency dependence of (a) $M^{\prime}$ and (b) $M^{\prime \prime}$ calculated over the temperature range of -60 to $10{ }^{\circ} \mathrm{C}$ for $\beta$-relaxation of 75 wt \% MAPM-silanated ZS-filled UDMA with MC of $6.0 \mathrm{wt} \%$.
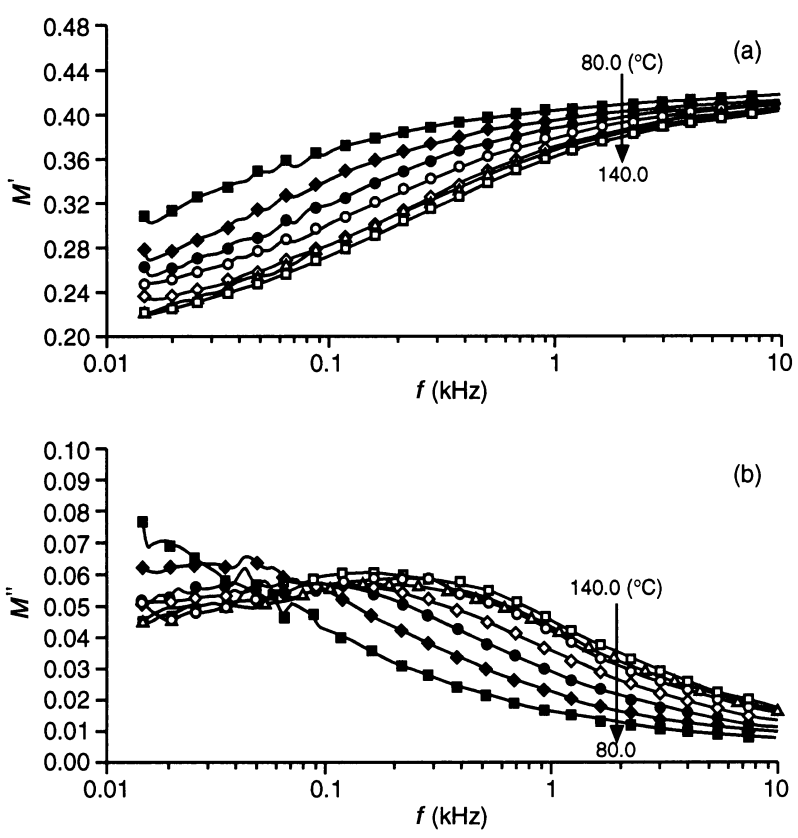

Fig. 9. The frequency dependence of (a) $M^{\prime}$ and (b) $M^{\prime \prime}$ calculated over the temperature range of $80-140{ }^{\circ} \mathrm{C}$ for $\alpha^{\prime}$-relaxation of $75 \mathrm{wt} \%$ MAPM-silanated ZS-filled UDMA with MC of $6.0 \mathrm{wt} \%$.

(1980) based on heat capacity measurements of water sorption in proteins has shown that the first water added interacts predominantly with ionizable groups 
Table 8. Low- $\left(\varepsilon_{0}\right)$ and high $\left(\varepsilon_{\infty}\right)$ frequency limiting values of $\varepsilon^{\prime}$ as well as dielectric increments $(\Delta \varepsilon)$ for $\alpha$ - and $\beta$-relaxations at 170 and $-30{ }^{\circ} \mathrm{C}$ as a function of $\mathrm{MC}(\mathrm{wt} \%)$ in $75 \mathrm{wt} \%$ MAPMsilanated ZS-filled UDMA

\begin{tabular}{lccccccc}
\hline & \multicolumn{2}{l}{$\alpha$-Relaxation } & & \multicolumn{3}{l}{$\beta$-Relaxation } \\
\cline { 2 - 3 } MC wt $\%$ & $\varepsilon_{0}$ & $\varepsilon_{\infty}$ & $\Delta \varepsilon$ & & $\varepsilon_{0}$ & $\varepsilon_{\infty}$ & $\Delta \varepsilon$ \\
\hline 0.0 & 2.466 & 2.210 & 0.210 & 1.998 & 1.978 & 0.018 \\
2.5 & 2.142 & 1.992 & 0.150 & & 1.793 & 1.758 & 0.034 \\
4.0 & 2.555 & 2.226 & 0.328 & 2.139 & 2.072 & 0.066 \\
6.0 & 2.685 & 2.327 & 0.357 & & 2.130 & 2.051 & 0.079 \\
\hline
\end{tabular}

and restores the normal pK order among groups perturbed strongly through dehydration. Further, mechanical losses where the magnitude of the $\beta$-relaxation increased showed the stiffening effect of water in polyamides according to Kolarik and Janácek (1967). Therefore, it was concluded that the first amount of water added, interacted with the CO groups to form firmly bound water that causes stiffening of the polymer network.

Subsequent sorption of moisture caused more water molecules to break the hydrogen bonding existing in the polymer network, forcing the chains to large mutual distances and exerting a plasticizing effect. This condition results in an increase in the number of free amide groups and an increase in their mobility. Such an effect is observed by the shift of the $\beta$-relaxation peak to low temperatures in the medium range of MC $>0.69-<3.0 \mathrm{wt} \%$. At high amounts of MC, the $\beta$-relaxation shifted to higher temperatures, which might be caused by either higher density of packing, the motion of moisture itself or both. The increase in the density is a result of the presence of hydrogenbound water molecules, which also hydrogen bond to the amide groups of the UDMA; as in the absence of water molecules the steric hindrance of the hydrogen bonds prevents the molecules from packing as closely as they would if Van der Waals' forces were dominant. So bonded water molecules lower the number of interchain hydrogen bonds to allow the molecules to pack more closely, thus increasing the polymer density. The motion of moisture is because of frozen and clustered water that forms a supercooled liquid or ice (Pathmanathan \& Johari, 1991). The reason for the anticipation of the motion of ice or quasi-ice structure in UDMA with $\mathrm{MC}>1.83 \mathrm{wt} \%$ is because the peak maximum shifted to $-40{ }^{\circ} \mathrm{C}$ at $1.0 \mathrm{kHz}$. At this temperature, usually the emulsified water crystallizes to hexagonal ice at $T \leq-40{ }^{\circ} \mathrm{C}$ during cooling. The validity of this anticipation along with the possibility of the higher density of packing at the high moisture content will be discussed later.

The magnitude of $\Delta \varepsilon$ for the UDMA with MC of $0.69 \mathrm{wt} \%$ is about 0.044 , which is higher than the dielectric increment of the dried UDMA (Table 3). This higher value indicates that the water molecules are attached strongly to the chain by hydrogen-bonding, thus involving chains' motion which contribute to the polarization and, hence, increase the dipole moment of the amide groups. In addition, the $\Delta \varepsilon$ for UDMA with the different MC increases rather rapidly for the moistened UDMA with MC at $1.0 \mathrm{wt} \%$, which confirms the overcoming of interchain coupling, as water has spread more onto the surface of the polymer and plasticized it. Thus, it forces the chains further apart and increases the average interchain distance between the hydrogen-bonded crosslinks. This situation will increase the number of free amide groups and increase their mobility according to Boyd (1959). Further, the $\Delta \varepsilon$ for UDMA with the high $M C \geq 1.83$ showed a new behaviour with increasing temperature which is presented in Fig. 10. The $\Delta \varepsilon$ showed an increase followed by a temperature independent region. From this behaviour, it seems that a change which is thermodynamic

Table 9. Activation energies, intensities $(\lambda)$ of $\tan (\delta)_{\varepsilon}$ at $0.0252 \mathrm{kHz}$ and half-widths of $\varepsilon\left(\Delta_{1 / 2}\right)$ (decades) for $\alpha$-, $\beta$ - and $\alpha^{\prime}$-relaxations at $170,-45$ and $135^{\circ} \mathrm{C}$, respectively, as a function of MC (wt \%) in $75 \mathrm{wt} \%$ MAPM-silanated ZS-filled UDMA

\begin{tabular}{|c|c|c|c|c|c|c|c|}
\hline \multirow[b]{2}{*}{ MC wt \% } & \multicolumn{3}{|l|}{$\alpha$-Relaxation } & \multicolumn{3}{|l|}{$\beta$-Relaxation } & \multirow{2}{*}{$\frac{\alpha^{\prime} \text {-Relaxation }}{\Delta_{1 / 2} 135\left({ }^{\circ} \mathrm{C}\right)}$} \\
\hline & $\Delta H(\mathrm{kcal} / \mathrm{mol})$ & $\lambda 0.252(\mathrm{kHz})$ & $\Delta_{1 / 2} 170\left({ }^{\circ} \mathrm{C}\right)$ & $\Delta H(\mathrm{kcal} / \mathrm{mol})$ & $\lambda 0.252(\mathrm{kHz})$ & $\Delta_{1 / 2}-45\left({ }^{\circ} \mathrm{C}\right)$ & \\
\hline $0 \cdot 0$ & $48 \cdot 5$ & 0.0120 & $4 \cdot 35$ & $10 \cdot 5$ & 0.0019 & $6 \cdot 60$ & - \\
\hline $2 \cdot 5$ & $38 \cdot 6$ & 0.0177 & $3 \cdot 32$ & $10 \cdot 6$ & $0 \cdot 0047$ & $5 \cdot 08$ & - \\
\hline $4 \cdot 0$ & $20 \cdot 6$ & $0 \cdot 1554$ & $2 \cdot 70$ & $5 \cdot 4$ & 0.0086 & $4 \cdot 69$ & $2 \cdot 25$ \\
\hline $6 \cdot 0$ & $32 \cdot 4$ & $0 \cdot 1880$ & $2 \cdot 76$ & $16 \cdot 0$ & 0.0101 & $2 \cdot 95$ & $2 \cdot 32$ \\
\hline
\end{tabular}




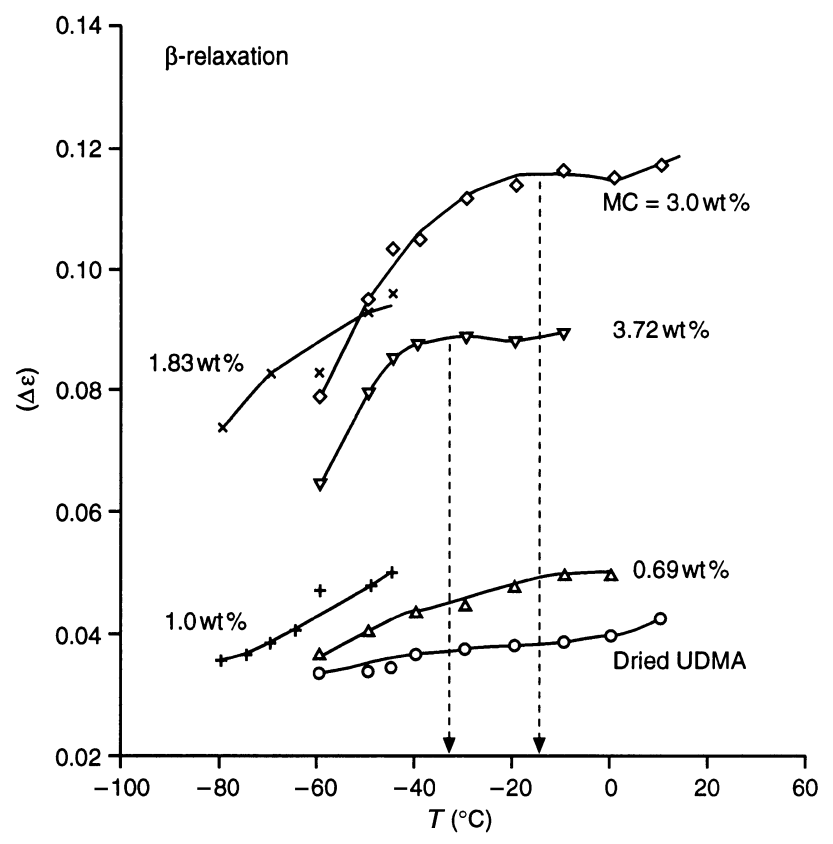

Fig. 10. Dielectric increments of $\beta$-relaxations against temperature for UDMA polymer with MC of $0,0.69,1 \cdot 0,1 \cdot 83,3.0$ and $3.72 \mathrm{wt} \%$.

in nature has occurred that disappears at low temperature.

To look into the temperature independence of the $\Delta \varepsilon$ more closely, one would suspect that the thermodynamic change is a phase transition of the water molecule to crystal or supercooled liquid. Usually, if micron-sized droplets existed, one would observe a dispersion around $-138{ }^{\circ} \mathrm{C}$ as a result of the $T_{\mathrm{g}}$ of a hyperquenched glassy water, and upon heating a second dispersion at $-43{ }^{\circ} \mathrm{C}$ might appear as a result of water crystallization to ice (Pathmanathan 8 Johari, 1991). The first dispersion is lacking in our measurements, while the later dispersion can be observed with MC $>1.83$ wt $\%$.

To examine the nature of the later dispersion, one can look at the change in the dielectric increment, $\varepsilon_{0}$ and $\varepsilon_{\infty}$ during the process, and compare them with those of ice clathrates. For instance, the $\Delta \varepsilon$ increased rapidly and reached a limiting magnitude of 0.094 with MC of $3.72 \mathrm{wt} \%$ at $-30{ }^{\circ} \mathrm{C}$. This magnitude is more than twice the value of 0.038 measured for vacuumdried UDMA at the same temperature. A $\Delta \varepsilon$ of about 40 would require that all the water in the material has crystallized to ice, for example, the dielectric increments for hexagonal ice and structural I and II clath- rates hydrates at these temperatures are about 117 (Jain \& Johari, 1990) and 50 (Pathmanathan et al., 1989), respectively. As $\Delta \varepsilon$ for moistened UDMA with MC of $3.72 \mathrm{wt} \%$ is much less than these values, one can assume that the water molecules in the hydrogenbonded network have not crystallized to any phases of ice and they have much lower degree of rotational freedom. However, the dielectric increments as stated above (Fig. 10) showed an independent temperature region at MC $>1.83 \mathrm{wt} \%$ which is similar to a transition to a different structural state. This behaviour implies slowness of the orientational correlation factor and the dielectric permittivity. Such behaviour indicates the formation of disordered structures composed of monomers or dimers and/or the assembly of higher disordered non-freezing clusters of water bonded to the amide groups which restricted their motion, although the amide groups of the UDMA are less restricted than those bonded by the tightly H-bound water molecules with the lowest MC.

The high frequency permittivity $\varepsilon_{\infty}$ of 1.832 at $-30{ }^{\circ} \mathrm{C}$ for high MC represents a combined magnitudes of the corresponding values of $\varepsilon_{\infty}$ of the hydrogen-bonded water and of the UDMA network structures. The open $\mathrm{H}$-bonded structures formed by the water molecules, have $\varepsilon_{\infty}$ values much $<3.0$ and for the various phases of ice are between 3 and 3.6 (Pathmanathan 8 Johari, 1991). As $\varepsilon_{\infty}$ of the UDMA at $-30{ }^{\circ} \mathrm{C}$ is 1.546 which is $18.5 \%$ lower than that of the moistened UDMA, it would seem that the network structure of water in UDMA has started to form into fragments of small units of non-freezing disordered water structures. In addition, the values of $\varepsilon_{0}$ and $\varepsilon_{\infty}$ for the $\alpha$ - and $\beta$-processes provide an insight as to whether crystallization occurs in moistened UDMA. At $-30{ }^{\circ} \mathrm{C}, \varepsilon_{0}$ is about 1.661 for the $\beta$-relaxation, while the $\alpha$-relaxation has a value of about $2 \cdot 14$ at $175{ }^{\circ} \mathrm{C}$. As the $\varepsilon_{0}$ of the $\beta$-relaxation increases slightly with increasing temperature and no other relaxation processes were observed, one may compare these values and observe that they are continuous and no abrupt change in their value occurs. This implies that moistened UDMA does not undergo any phase transition in this relaxation. Therefore, this behaviour along with the shifting of this region of change toward higher temperatures and the presence of abundant water molecules, might imply two simultaneous mechanisms. The first mechanism is that the water molecules tend to hydrogen 
bond with each other to form fragments of clusters of water molecules. These fragments lack freezing and crystallinity and bind to the amide groups to restrict their motion. The second mechanism is that the water molecules replace the hydrogen bonds existing between the amide groups, thus lowering the number of interchain hydrogen bonds in the polymer to allow the molecules to pack more closely and increasing the polymer density.

Although the half-width $\left(\Delta_{1 / 2}\right)$ of the $\beta$-process became narrower on the addition of small amount of moisture to the UDMA, the typical features of the half-width of the local mode motions persisted. That is, the spectra broadens and heights of $\varepsilon^{\prime \prime}$ decreases with decreasing temperature (Fig. 2). Such narrowing in the half-width indicates that the mobility of the local chain motion is more restricted, which implies that the distribution of the dipolar environment is much smaller in the moistened UDMA than the dry UDMA. Subsequent addition of moisture increased the $\Delta_{1 / 2}$ to a limiting value of 3.65 decades for the UDMA with MC $\geq 3.0 \mathrm{wt} \%$ (Table 2). This result is higher than the 1.5 decades observed for ice (Pathmanathan et al., 1989) and indicates the broadening of the distribution of the relaxation times because of the different environments of water molecules. Also, it might contain the different distribution times because of differently plasticized local chains in the polymer network.

The change in the apparent activation energy $(\Delta H)$ of the $\beta$-relaxation increased to higher values with the addition of a small amount of moisture. The $\Delta H$ increased from $7.5 \mathrm{kcal} \mathrm{mol}^{-1}$ for pure UDMA to $12.2 \mathrm{kcal} \mathrm{mol}^{-1}$ for UDMA with MC of $0.69 \mathrm{wt} \%$. Such an increase further supports the increase in interchain coupling and chain stiffening because of tightly bound hydrogen bonds that occur between the water molecules and the amide groups. The activation energy of the relaxation process decreased to lower values upon further addition of water, showing the ease of motions of the local chains because of the plasticization effect of water. Finally, the change in energy increased to a limiting value of $10.6 \mathrm{kcal} \mathrm{mol}^{-1}$ for the UDMA with $M C \geq 3.0 \mathrm{wt} \%$. This increase in the values is because of the restriction of the motion of amide groups due to closely packed polymer and closely packed regions around the amide groups of the UDMA that are created by the hydrogen-bonded water molecules.
The effect of moisture on the $\alpha$-relaxation. As the $\alpha$-relaxation is a result of large segmental motion of the molecular chains in the UDMA polymer, their loosening or stiffening controls the orientation of the amide groups (Mohsen et al., 1999). Logically, the effect of moisture on the dielectric parameters of the $\alpha$-relaxation for UDMA, will be discussed in terms of the relationship to the orientation of the amide groups. Further, the effect of MC $\geq 3.0 \mathrm{wt} \%$ on the dielectric parameters of the $\alpha$-relaxation could not be resolved because of its obstruction by the appearance of a new peak, whose origin will also be discussed.

The main feature of the effect of moisture on the dielectric spectrum was the occurrence of a new separate loss peak $\left(\alpha^{\prime}\right)$ that obstructed the observation of the $\alpha$-relaxation (Fig. 1). This loss peak started to manifest itself in the low frequency and high temperature region for the moistened UDMA with MC $\geq 1.83 \mathrm{wt} \%$ and developed completely for the UDMA with $M C \geq 3.0 \mathrm{wt} \%$ (Fig. 3). This loss peak was attributed to the interfacial or MWS polarization, which is developed because of charge mobility at the interface between the polymer and water inclusions, and developed only after the formation of a certain size of water droplets that are not stabilized by hydrated polar groups. These droplets started to form interfacial hydrated structures on the amide groups of the UDMA and developed interfacial monolayers of surface active agents. These same interfacial monolayers, composed of hydrated water molecules that are hydrogen bonded to each other and to the amide groups, caused the restriction of the motion of the amide groups.

To examine the characteristics of the MWS polarization $\left(\alpha^{\prime}\right)$, the $\Delta \varepsilon$, half-width and activation energy were studied. The $\Delta \varepsilon$ values for this relaxation have a maximum when plotted against temperature in the region of the relaxation as is shown in Fig. 11. The peak maximum of $\Delta \varepsilon$ for the UDMA with MC of $3.0 \mathrm{wt} \%$ appeared at $170{ }^{\circ} \mathrm{C}$, while it appeared at $160{ }^{\circ} \mathrm{C}$ for the UDMA with MC of $3.72 \mathrm{wt} \%$. Such a peak maximum can be explained by an ordering and disordering mechanism of the dipole arrangements of the hydrated structures on the amide groups and are similar to those that occur in the glass transition region (Baird, 1967; Hedvig, 1977). As the application of the electric field reduces the disorder of the dipole by aligning it with the field, it decreases the configuration entropy of the system. However, increasing the tem- 


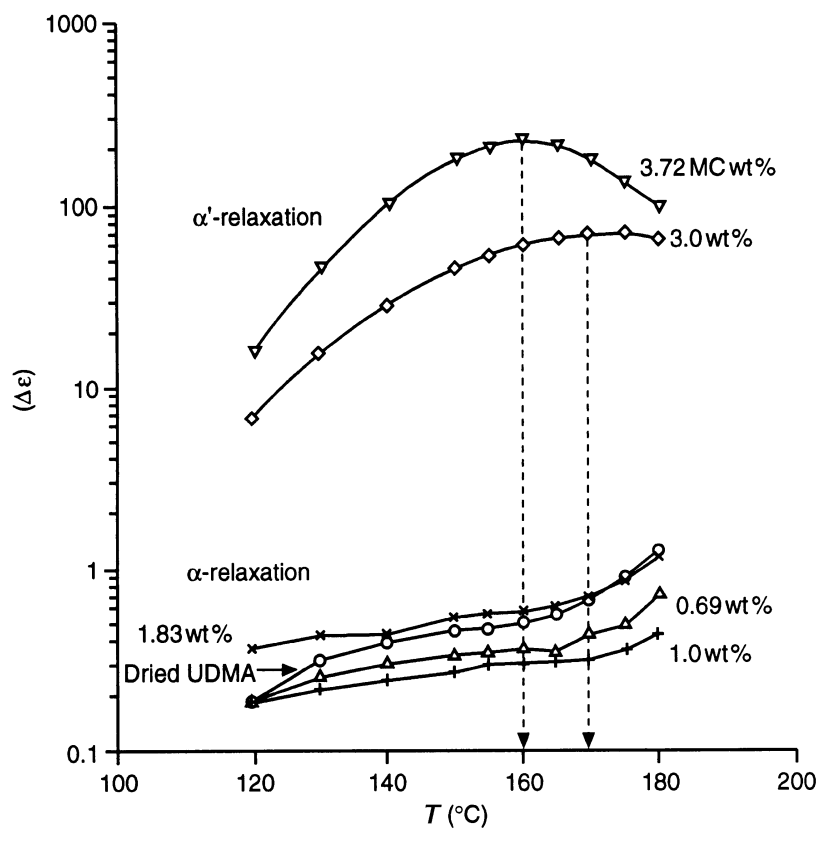

Fig. 11. Dielectric increments of $\alpha$ - and $\alpha^{\prime}$-relaxations against temperature for UDMA polymer with MC of $0,0 \cdot 69,1 \cdot 0,1 \cdot 83,3 \cdot 0$ and 3.72 wt $\%$.

perature before reaching the $\Delta \varepsilon$ peak maximum would increase the configuration entropy and the disorder of the dipole arrangement, until the field has no effect on the entropy and the peak maximum is reached. Upon further increasing the temperature, the field starts to decrease the entropy by orienting some of the dipole. Also, the $\Delta \varepsilon$ values for this relaxation increased with MC. The values were very high and they almost double from 70.46 for the UDMA with MC of $3.0 \mathrm{wt} \%$ to $120 \cdot 10$ with MC of $3.72 \mathrm{wt} \%$. Such high values are the result of high mobility and high deformation of the dispersed water droplets. The difference in the $\Delta \varepsilon$ values between 3.0 and $3.72 \mathrm{wt} \%$ moistened UDMA is probably caused by the size of the dispersed water droplets.

The half-width of this relaxation decreased with the increase in MC and reached a limiting value of 1.26 decades for the UDMA with MC of $3.72 \mathrm{wt} \%$ (Table 2). This value is higher than the value of $1 \cdot 14$ decades for the single relaxation behaviour, which indicates that the slight widening of the distribution of relaxation time might be caused by non-uniformity of conductivity of the hydrated structures on the amide groups. In addition, the activation energy values were reduced with the increase in MC of the UDMA and reached a limiting value of $8.0 \mathrm{kcal} \mathrm{mol}^{-1}$ (Table 2).
The $T_{\mathrm{g}}$ of the $\alpha$-relaxation was affected slightly with the addition of small amount of moisture to the UDMA (Table 1; Fig. 1); however, it decreased severely with high MC. This effect has been interpreted to be an increase in the free volume with increasing temperature and the consequent loosening of the interchain and/or intra-segmental motion as reported by Chan et al. (1986), thus plasticizing the polymer and increasing the number of the free amide groups.

In general, the dielectric increment of the glass transition region reaches a maximum value when plotted against temperature (Baird, 1967; Hedvig, 1977). The $\Delta \varepsilon$ in UDMA, however, increased slightly with temperature as is shown in Fig. 11 after a temperature independence region. This temperature independence region is equivalent to the onset of the maximum with increasing temperature, which could not be resolved because of the inaccuracy of determining $\Delta \varepsilon$, as a result of the obstruction of the $\alpha$-relaxation by the DC conductivity. Although such behaviour persisted for the moistened UDMA, the $\Delta \varepsilon$ values decreased with small amount of MC and then increased with higher amount (Table 3). On one hand, the decrease in the $\Delta \varepsilon$ values along with the change of the $T_{\mathrm{g}}$ values (Table 1) for the UDMA with low MC confirms that the stiffening of the main chains had occurred, thus decreasing the dipole moment of the chains. On the other hand, the increase in the $\Delta \varepsilon$ values for the UDMA with MC indicates that the water molecules attached to the chain through hydrogen bonding at the amide groups are contributing to the polarization.

Finally, moisture has a strong plasticizing action as evidenced by the reduction in the activation energy (Table 2) and was highly noticed with large amounts of moisture. The plasticization may be because of two effects, the result of interchain bonding by the replacement of amide-amide hydrogen bonds and increasing the mobility of the segmental chains by dilution.

The effect of moisture on the dielectric behaviour of ZS-filled UDMA

The effect of moisture on the $\beta$-relaxation. At low MC, the $\beta$-relaxation of the $75 \mathrm{wt} \%$ ZS-filled UDMA resemble those of the UDMA. The sorbed moisture restricted the motion of the amide groups by increasing the intermolecular bond in the polymer network. Such restriction was achieved by the water molecules, when they form 


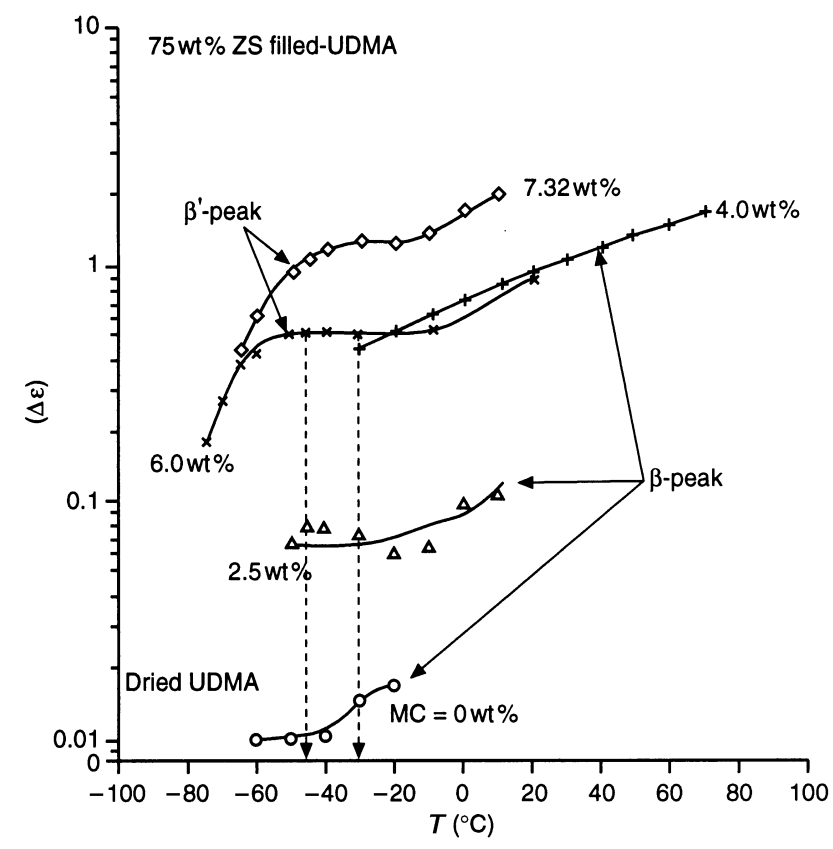

Fig. 12. Dielectric increments of $\beta$-relaxations against temperature for $75 \mathrm{wt} \% \mathrm{ZS}$-filled UDMA polymer with MC of $0,2 \cdot 5,4 \cdot 0$, 6.0 and 7.32 wt $\%$.

tight hydrogen bonds between two $\mathrm{CO}$ groups in the polymer and loose hydrogen bonds between $\mathrm{CO}$ and $\mathrm{NH}$ groups. This conclusion was based on the following results: (i) the gradual shift of the peak maximum of $\tan (\delta)_{\varepsilon}$ to higher temperatures with sorption of small amount of moisture until it reached a maximum temperature of $10.0{ }^{\circ} \mathrm{C}$ for $\mathrm{MC}$ of $4.0 \mathrm{wt} \%$ at $0 \cdot 252 \mathrm{kHz}$ (Table 4), (ii) the $\Delta \varepsilon$ increased gradually with temperature (Fig. 12) and rapidly with MC (Table 5) indicating that the orientation of the dipole of the composite increased with temperature and with moisture, (iii) the half-width of the local motion persisted, i.e. broadening with decreasing temperature, while their values increased with MC (Table 6) indicating the increase in the distribution of relaxation time, and implying the presence of diverse species of water molecules that have different relaxation times with higher MC, (iv) the increase in the intensity of the $\tan (\delta)_{\varepsilon}$. most equal to those for the UDMA values (Tables 2 and 6) and (v) the increase in the change of the activation energy from $6.7 \mathrm{kcal} \mathrm{mol}^{-1}$ for $75 \mathrm{wt} \%$ ZS-filled UDMA with MC of $0 \mathrm{wt} \%$ to $15.9 \mathrm{kcal} \mathrm{mol}^{-1}$ with MC of $4.0 \mathrm{wt} \%$ (Table 6).

At high MC, the results show resemblances and differences in the behaviour of the $\beta$-relaxation for the
75 wt \% ZS-filled UDMA compared with those of the unfilled-UDMA. Like the unfilled-UDMA, the peak maximum of the $\tan (\delta)_{\varepsilon}$ for the composite shifted to lower values and then increased to approach a limiting value. In addition, the $\Delta \varepsilon$ values increased until they reached a temperature independent region with increasing temperature. Further the $\Delta_{1 / 2}$ reached a similar value of 3.31 decades at $-45.0{ }^{\circ} \mathrm{C}$, and the intensities of the $\tan (\delta)_{\varepsilon}$ also increased with MC. These results indicate that the water molecules tend to plasticize the polymer by separating the chains, resulting in increasing numbers of free amide groups and their mobility. However, the shift of the relaxation to higher temperature for the composite with MC of $7 \cdot 32 \mathrm{wt} \%$ indicates (i) the restriction of the amide groups mobility because of higher density of packing of the polymer and (ii) the formation of fragments of clusters of water molecules that are hydrogen bonded to each other and to the amide groups.

Unlike the unfilled-UDMA, the low frequency dielectric constant $\left(\varepsilon_{0}\right)$ for the composite with MC of $7.32 \mathrm{wt} \%$ is 3.988 and is increased by $55 \%$ from the value of the dried composite, indicating that the orientational correlation of the dipole moments has increased drastically for the moistened composite. However, such magnitude is lower than the values estimated for ice on the basis of the data presented in the literature (Takashi et al., 1982; Jain \& Johari, 1988; Pathmanathan \& Johari, 1991). In addition, the high frequency dielectric constant $\left(\varepsilon_{\infty}\right)$ of 2.7 at $-30{ }^{\circ} \mathrm{C}$ for the high MC represents statistically the combined magnitudes of the corresponding values of $\varepsilon_{\infty}$ of a hydrogen-bonded water structure and of the UDMA network structures. The open hydrogen-bonded structures formed by the water molecules such as those in clathrates, have $\varepsilon_{\infty}$ values much $<3.0$ (Jain $\&$ Johari, 1988; Pathmanathan $\&$ Johari, 1991). The present results show that the combined magnitudes of the hydrogen-bonded water structure and of the UDMA network structures are in fact $<3$. Further, the values of $\varepsilon_{0}$ and $\varepsilon_{\infty}$ for $\alpha$ - and $\beta^{\prime}$-processes provide an insight into the state of the water that occurs in the composite. At $0{ }^{\circ} \mathrm{C}, \varepsilon_{0}$ is about 5.3 for the $\beta$-process, while the $\alpha$-process has a value of about $4 \cdot 1$ for $\varepsilon_{\infty}$ at $20^{\circ} \mathrm{C}$. As no other relaxation processes were observed between 0 and $20{ }^{\circ} \mathrm{C}$, the lower the value of $4 \cdot 1$ for the $\varepsilon_{\infty}$ for the $\alpha$-relaxation compared with 5.3 for $\varepsilon_{0}$ for the $\beta$-relaxation implies that some phase transition has taken place in the composite over this temperature range. Also, the 
$\varepsilon_{\infty}$ increases from 4.8 at $50{ }^{\circ} \mathrm{C}$ to about $5 \cdot 2$ at $70{ }^{\circ} \mathrm{C}$. These observations suggest that there is melting of partially crystallized ice that continues with increasing temperature.

Although the dielectric increment for the $\beta$-relaxation is a monotonous function of the temperature, the $\Delta \varepsilon$ values increased as a function of temperature to reach a maximum above the transition of the $\beta^{\prime}$-relaxation for the $75 \mathrm{wt} \%$ ZS-filled UDMA with MC $\geq 6.0$ wt \% (Fig. 12). This observation indicates a persistence of a thermodynamic change in this region and a gradual onset of a decrease in $\Delta \varepsilon$ beginning at these temperatures and a beginning of a transition to a more ordered structural state of low dielectric permittivity. Such a transition might be a result of ordering and disordering mechanism of the hydrogen-bonded water structures and their fragmented clusters to form partially ordered ice structures. This transition is similar to phase transition of ice III $\rightarrow$ IX transition where a gradual decrease in the orientational polarization occurs and at all temperatures in the transformation range, ice III is partially disordered (Pathmanathan et al., 1989). Further, the shift of the maximum of the $\Delta \varepsilon$-values and the peak of the $\tan (\delta)_{\varepsilon}$-values to higher temperatures with the increase of $\mathrm{MC}$ indicates that more partial ordering might be occurring. This proposal is supported by Jain and Johari (1988) who showed that crystallization of $\mathrm{H}$-bonded structures in amorphous aqueous poly(vinylpyrrolidone) shifted the dispersion peak to higher temperature.

The half-width of $\beta$-relaxation for the $75 \mathrm{wt} \%$ ZS-filled UDMA became constant from $-50-10{ }^{\circ} \mathrm{C}$ with the increase of $\mathrm{MC}$ and broadened until a maximum value was reached of 6.48 decades with MC of $4.0 \mathrm{wt} \%$. Eventually, the $\Delta_{1 / 2}$ became narrower and reached a value of 3.31 decades of frequency with MC of $7.32 \mathrm{wt} \%$. The widening of the half-widths of the spectra indicates broadening of distribution of relaxation time at low MC, while the narrowing indicates restraining of the distribution because of the decrease of the number of the different water environments. Although the $\Delta_{1 / 2}$-value of 3.31 decades for the composite with MC of $7.32 \mathrm{wt} \%$ is lower than the $\Delta_{1 / 2}$ of the moistened composite with MC of $6.0 \mathrm{wt} \%$, it is still higher than the dried composite and much higher than the 1.5 decades observed for the ice by Pathmanathan et al. (1989). Part of the increased half-width may be caused by the condition that the composite contained several different environments of water molecules, such as randomly oriented disordered crystals at the interface, non-freezing fragments of water clusters in the polymer phase and hydrogen-bonded water molecules with each other and with the amide groups. These different environments of reorienting water molecules may cause such a wide distribution of the spectra.

The activation energy also increased and then decreased to a value of $17.9 \mathrm{kcal} \mathrm{mol}^{-1}$ for the reorientation of water molecules in the UDMA composite. Such a value is much higher than activation energy found for ice clathrates $\left(13 \mathrm{kcal} \mathrm{mol}^{-1}\right.$ ) (Takashi et al., 1982; Jain \& Johari, 1988; Pathmanathan et al., 1989; Pathmanathan \& Johari, 1991). But in hydrogenbonded structures with disordered arrangements of water molecules, as in aqueous poly(vinylpyrrolidone) glasses (Jain \& Johari, 1988, 1990), glucose and water mixture (Chan et al., 1986), and glassy water (Pathmanathan et al., 1989; Pathmanathan \& Johari, 1991), the activation energy is higher than the $13 \mathrm{kcal} \mathrm{mol}^{-1}$. This indicates further that most of the water molecules are disordered, non-freezing and open hydrogen-bonded structures.

The effect of moisture on the $\alpha$-relaxation. The main feature of the effect of moisture on the dielectric spectrum of the composite was the occurrence of the $\alpha^{\prime \prime}$ peak with MC $\geq 4.0 \mathrm{wt} \%$. This peak was attributed to superposition of the effects of the interfacial polarization and phase transition. The phase transition was associated with moisture evaporation that existed in the region of the interface. The $\alpha^{\prime \prime}$ peak differs from the $\alpha^{\prime}$ peak that occurred for the moistened unfilled UDMA, because of its shift to lower frequency and the increase in its height with the increase in the temperature until it disappeared (Fig. 6).

The values of $\varepsilon_{0}$ and $\varepsilon_{\infty}$ for the $\alpha$-process before and after the occurrence of the $\alpha^{\prime \prime}$ process for the composite with MC $7.32 \mathrm{wt} \%$ provide an insight into the evaporation that occurs in the interface region of the composites. As the $\alpha^{\prime \prime}$-relaxation occurs over the temperature range of $70-150{ }^{\circ} \mathrm{C}$, the $\varepsilon_{0}$ value is 11.9 at $70{ }^{\circ} \mathrm{C}$, while the $\varepsilon_{\infty}$ of the $\alpha$-relaxation is 3.3 at $155^{\circ} \mathrm{C}$. This low value of 3.3 for $\varepsilon_{\infty}$ for the high temperature region of the $\alpha$-relaxation as compared with 11.9 for $\varepsilon_{o}$ for the low temperature region implies that the moisture at the interface has undergone a phase transition. The decrease of the half-width of the $M^{\prime \prime}$ peak for the $\alpha^{\prime \prime}$ relaxation from 5.87 decades to 3.40 decades for an increase of $10^{\circ} \mathrm{C}$ indicates that the dipolar processes 
have different sensitivities to temperature. Further, the moisture does not only occupy the interfacial region in the composite but it also plasticizes the UDMA polymer.

As the maximum MC that can be sorbed for the composite is $7.32 \mathrm{wt} \%$ and for the UDMA polymer is $3.72 \mathrm{wt} \%$, one would assume that the extra moisture that was sorbed by the composite is at the interface and/ or in the voids. This assumption implies that plasticization effect in the polymer part of the composite will be equivalent to that of the polymer. However, by looking at the different results such as the shift of the $\alpha$-relaxation peak temperature to lower values and the decrease in the activation energy values, one notices that the values for the moistened composites are drastically more affected than the values for the moistened UDMA. For instance, the peak maximum of the $\tan (\delta)_{\varepsilon}$ was shifted to lower values by $20{ }^{\circ} \mathrm{C}$ for the unfilled-UDMA with MC of $3.00 \mathrm{wt} \%$ at $5.5 \mathrm{kHz}$ (Table 1), while it decreased by about $25{ }^{\circ} \mathrm{C}$ with the small introduction of moisture and decreased by about $50{ }^{\circ} \mathrm{C}$ over the entire moisture content at $0.5 \mathrm{kHz}$ for the moistened composites (Table 4). The activation energy values decreased by about $28.8 \mathrm{kcal} \mathrm{mol}^{-1}$ for the moistened unfilled UDMA from the value of the dried UDMA, while it was decreased by about 32.5 $\mathrm{kcal} \mathrm{mol}^{-1}$ for the moistened composites from the value of the dried composites. These results suggest that the filler in the composites decreases the density of packing of the polymer at the boundary layer, thus allowing more water molecules to enter between the chains and exposing more chains to react with the water. This condition could result in a larger increase in the distance between the chains and, consequently, more loosening of the network.

The effect of moisture on the dielectric behaviour of MAPM-silanated ZS-filled UDMA

The effect of moisture on the $\beta$-relaxation. The $\beta$-process for the composite shows exactly the same behavior as those of the UDMA polymer, namely, with small amount of moisture, an overall stiffening of the composite occurred, as indicated by the shift of the $\beta$-peak maximum of the $\tan (\delta)_{\varepsilon}$ to higher temperatures (Table 7), the decrease of the half-width of the bands from 6.60 to 5.08 decades for the moistened composite with MC of $2.5 \mathrm{wt} \%$ (Table 9), and the insignificant increase in the change of the activation energy (Table 9).
With more moisture sorption, the water molecules replaced more $\mathrm{H}$-bonds in the composite, and plasticization effect developed, demonstrated mainly by the shift of the $\beta$-peak maximum value to $-90 \cdot 0{ }^{\circ} \mathrm{C}$ for the moistened composite at $4.0 \mathrm{wt} \%$ at $1.0 \mathrm{kHz}$, and the decrease of the activation energy to 5.4 kcal mol ${ }^{-1}$.

When the maximum amount of moisture sorption is achieved, water fragments and clusters between the polymer chains developed, which restricted the chain motion and increased the polymer density. This result was observed by the increase of the peaks maximum to higher temperatures, the increase in the values of the activation energies and narrowing of the distribution of the relaxation times, as depicted from the decrease of $\Delta_{1 / 2}$-values (Table 9).

The effect of moisture on the $\alpha$-relaxation. The overall effect of moisture was to plasticize the composite by breaking its interchain coupling, as was shown for the UDMA polymer system. However, in the composite with silanated filler, as well as unsilanated filler, the plasticization was more severe than for the pure UDMA polymer, especially for the composite containing unsilanated filler, as the shift in the $\alpha$-peak was at least $50{ }^{\circ} \mathrm{C}$ at $0.5 \mathrm{kHz}$. In the case of composite with silanated filler, water plasticization was less severe than for the composite with unsilanated filler and more severe than the polymer. This observation may be attributed to the breakage of the siloxane bonds that are formed between the filler and the silane or it may be the result of water molecules attacking the filler surface at sites incompletely covered by the silane molecules which may result in dilution and the formation of less well packed layer at the boundary, increasing the segmental mobility.

Like the polymer, a new peak $\left(\alpha^{\prime}\right)$ was developed (Fig. 9) that obstructed the $\alpha$-relaxation. This peak was attributed to the separation of charges that occurred between the water droplets and the hydrated polar groups to form an interfacial monolayer of surface active agent.

In general, the quantities such as $\Delta \varepsilon$ and $\Delta_{1 / 2}$ showed that there is more non-uniformity of the hydrated structures on the amide groups in the interfacial monolayer for the composite than those for the polymer. For instance, the $\Delta \varepsilon$ of the $\alpha^{\prime}$-relaxation increased with the increase in MC and formed a peak maximum with temperature about $135{ }^{\circ} \mathrm{C}$ (Fig. 13) for the composite with silanated filler. This result implies that the 


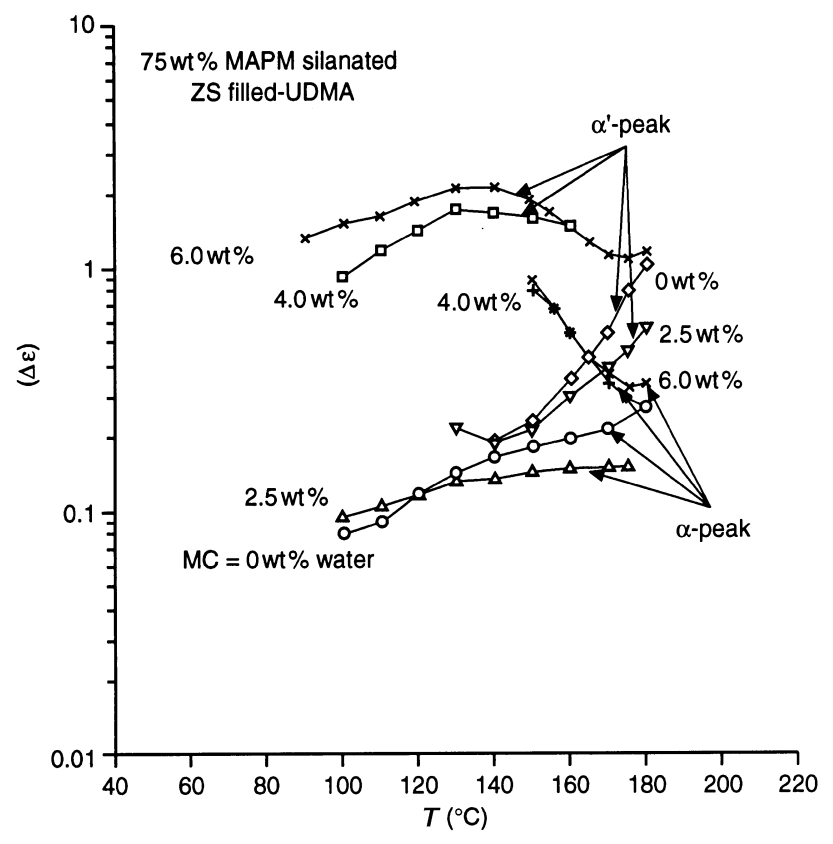

Fig. 13. Dielectric increments of $\alpha$ - and $\alpha^{\prime}$-relaxations against temperature for $75 \mathrm{wt} \%$ MAPM-silanated ZS-filled-UDMA polymer with MC of $0,2 \cdot 5,4 \cdot 0$ and $6 \cdot 0 \mathrm{wt} \%$.

ordering and disordering of the dipole arrangement in the composite is much easier than in pure UDMA $(\Delta \varepsilon$ peak maximum $=160{ }^{\circ} \mathrm{C}$ ) with temperature and with the electric field. In addition, the half-width was 2.32 decades of frequency with MC of $6.0 \mathrm{wt} \%$ for the composite with silanated filler (Table 9), and it was 3.56 decades for the composite with unsilanated filler, while it was 1.26 decades for the UDMA with MC of 3.72 wt \% (Table 2 ).

The mechanism of moisture in UDMA polymer and composite

The previous discussion of the water sorption process in dry UDMA fits the following picture, which follows closely a description by Puffer and Sebenda (1967) and which is illustrated in Fig. 14. (A) The dry UDMA polymer molecule makes few contacts with neighbouring molecules. (B) The first water added interacts predominantly with the carbonyl groups forming tight bonds. This strongly bound water $(\mathrm{MC}=0.69 \mathrm{wt} \%)$ is dispersed about the UDMA surface and constitutes about $18.5 \mathrm{wt} \%$ of the moisture sorbed in the polymer. (C) At higher water content, the water molecules start to break and replace the hydrogen bonds that exist between the amino and carbonyl

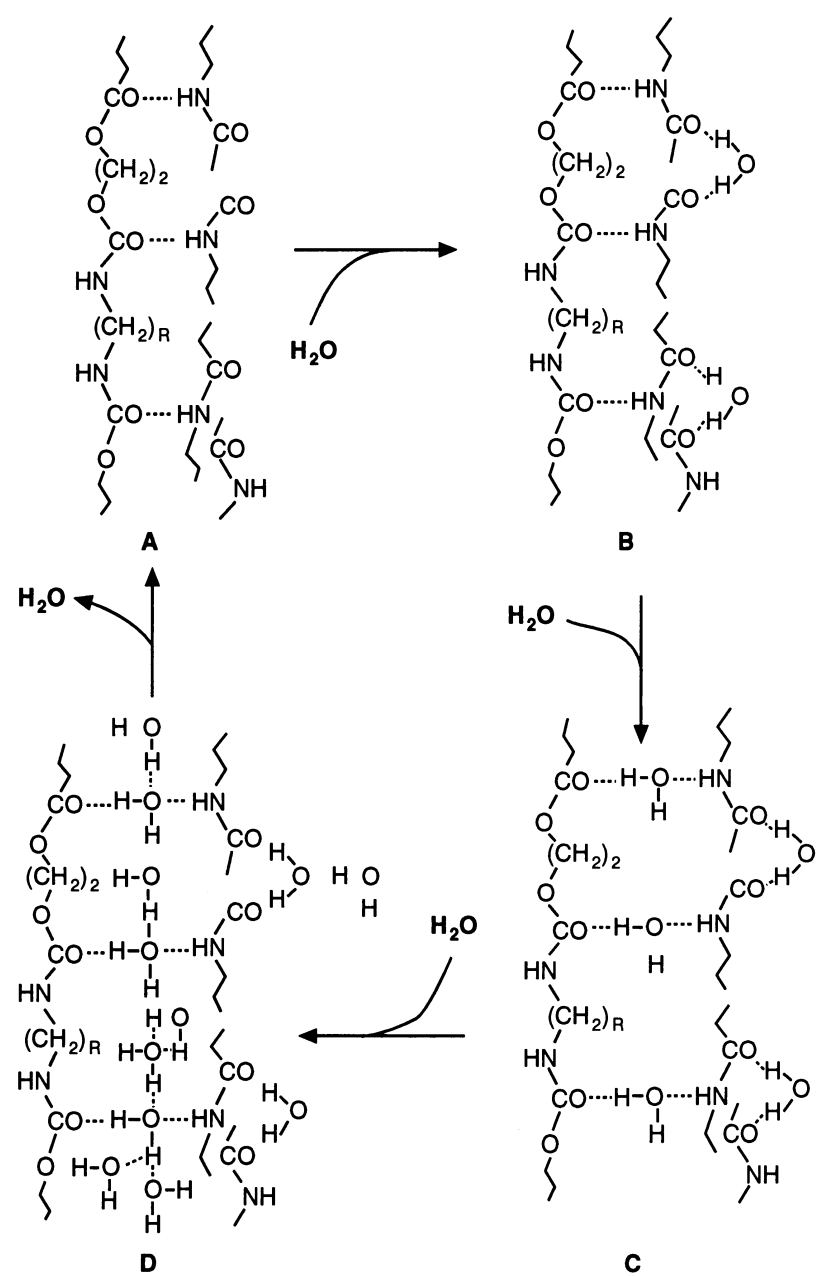

Fig. 14. Representation of the events of water sorption process in UDMA polymer. Letters correspond to discussion in the text.

groups forming loosely bound water. This type of water causes loosening of the chains and increases the number of free amide groups. (D) At about $49 \mathrm{wt} \%$ of the sorbed moisture in the polymer, clusters develop presumably around the polar groups. This proposal was established from the variability of the hydrogen bonding arrangements in the polymer as was seen in the broadening of the distribution of relaxation time (Table 2), the development of MWS polarization indicating the presence of interfacial monolayer that contains unstable hydrated polar groups and the restriction of the amide group's mobility. In UDMA polymer, the maximum water that can be sorbed into the polymer is MC of $3.72 \mathrm{wt} \%$ at $100{ }^{\circ} \mathrm{C}$, indicating that water can only form clusters in the UDMA polymer and does not form a monolayer or become bulk water. 
In the ZS-filled UDMA, additional moisture is sorbed, and it accumulates at the interface between the filler and polymer or at the cracks and microvoids in the polymer or both, forming an interfacial layer. This layer contains different hydrogen bonding environments that mesh well with bulk water that can undergo phase transitions. These phase transitions were seen from the abrupt changes in the $\Delta \varepsilon$-values because of melting and evaporation of the bulk water. With increasing temperature, the bulk water causes major plasticization of the composites, thus lowering the $T_{\mathrm{g}}$ severely.

In the MAPM-silanated ZS-filled UDMA, the composites behaved more like the polymer, except with increasing temperature it is more plasticized than the polymer with increasing moisture content. Such plasticization is not as severe as for the composite with unsilanated filler and points out the importance of good silanation of fillers in dental composites. This plasticization is attributed to the breaking of the siloxane bonds that form between the filler and the silane coupling agent and/or the water molecules attacking the filler surface at sites incompletely covered by the silane molecules.

In conclusion, it has been demonstrated that measurements of dielectric relaxation are useful in understanding the effect of moisture on a UDMA polymer used in the formulation of dental composites and on the effectiveness of the silanation used to provide a bond between the organic and inorganic phases. This information should be useful in the development of improved dental composites. For example, it is important to minimize the hydrolytic degradation of the silanated layer in dental composites and to be able to measure its stability. Dielectric relaxation is a suitable measurement for such an assessment. The effectiveness of various silanes or combinations of silanes, as well as the effectiveness of the silanation process, could be evaluated with the objective of producing a dental composite that would be minimally plasticized by moisture, thus providing maximal mechanical strength in the presence of water or saliva.

\section{Acknowledgments}

This research was supported through the Center Grant from USPHS grant P50 DE 09296 from the National Institute for Dental Research, Bethesda, MD, 20892.

\section{References}

BAIRD, M.E. (1967) Some recent developments in the study of dielectric behaviour of polymers. In: Progress in Polymer Science (ed. A.D. Jenkins), Vol. 1, pp. 161. Pergamon Press, London.

Boyd, R.H. (1959) Dielectric loss in 66 nylon (polyhexamethylene adipamide). Journal of Chemistry and Physics, 30, 1276.

Brown, G.L. (1980) Clustering of water in polymers. In: Water in Polymers, ACS Symposium Series 127 (ed. S.P. Rowland), pp. 441. American Chemical Society, Washington DC.

Chan, R.K., Pathmanathan, K. \& Johari, G.P. (1986) Dielectric relaxations in the liquid and glassy states of glucose and its water mixtures. Journal of Physical Chemistry, 90, 6358.

DeOdHAR, S. (1980) Measurement of bound (nonfreezing) water by differential scanning colorimetry. In: Water in Polymers, ACS Symposium Series 127 (ed. S.P. Rowland). pp. 273. American Chemical Society, Washington DC.

HanaI, T. (1960) Theory of the dielectric due to the interfacial polarization and its application to emulsions. Kolloid-Zeitschrift, Band 171, 23.

Hedvig, P. (1977) Dielectric Spectroscopy of Polymers. John Wiley and Sons, New York.

JAIN, S.K. \& JohARI, G.P. (1988) Dielectric studies of molecular motions in the glassy states of pure and aqueous poly(vinylpyrrolidone). Journal of Physical Chemistry, 92, 5851.

JAIN, S.K. \& JoHARI, G.P. (1990) Conductance and relaxations in the glassy and rubber states of aqueous poly(vinylpyrrolidone): a cryofixation medium. Journal of Polymer Science: Part B: Polymer Physics, 28, 763.

Johnson, G.E., Bair, H.E., MAtsuokA, S., Anderson, E.W. $\delta$ ScotT, J.E. (1980) Water sorption and its effect on a polymer's dielectric behavior. In: Water in Polymers, ACS Symposium Series 127 (ed. S.P. Rowland), pp. 451. American Chemical Society, Washington DC.

KolARIK, J. \& JANÁCEK, J. (1967) Secondary ( $\beta-$ ) relaxation process of alkaline polycarloactam swollen by low molecular weight substances. Journal of Polymer Science: Part C, 16, 441 .

McCrum, N.G., Read, B.E. \& William, G. (1967) Anelastic and Dielectric Effects in Polymeric Solids. John Wiley and Sons, London.

Mohsen, N.M., Craig, R.G. \& Filisko, F.E. (2000) The effect of different additives on the dielectric relaxation of urethane dimethacrylate. Journal of Oral Rehabilitation, 27, 250.

Moynihan, C.T., Boesch, L.P. \& Laberge, N.L. (1973) Decay function for the electric field relaxation in vitreous ionic conductors. Physical Chemistry of Glasses, 14, 122.

PAthmanathan, K. \& JohARI, G.P. (1991) Dielectric and conductivity relaxations in poly(hema) and of water in its hydrogel. Journal of Polymer Science: Part B: Polymer Physics, 28, 675.

Pathmanathan, K., Johari, G.P. \& Ripmeester, J.A. (1989) Dielectric and calorimetric studies of $\beta$-cyclodextrin undecahydrate. Journal of Physical Chemistry, 93, 7491.

Puffer, R. \& SEBendA, J. (1967) On the structure and properties of polyamides. XXVII. The mechanism of water sorption in polyamides. Journal of Polymer Science: Part C, 16, 79. 
Rupley, J.A., YANG, P.H. \& Gordon, T. (1980) Thermodynamic and related studies of water interacting with proteins. In: Water in Polymers. ACS Symposium Series 127 (ed. S.P. Rowland), pp. 111. American Chemical Society, Washington DC.

Sмyтн, C. (1955) Dielectric Behavior and Structure. McGraw-Hill Book Company Inc., New York.

STARKWEATHER, H.W. (1980) Water in nylon. In: Water in Polymers, ACS Symposium Series 127 (ed. S.P. Rowland), pp. 433. American Chemical Society, Washington DC.
Takashi, H., Masayoshi, F., Shuji, Y. \& Tetsuo, K. (1982) The effect of moisture on the dielectric relaxation in wood. Journal of Applied Polymer Science, 27, 439.

VANBEEK, L. (1967) Dielectric behaviour of heterogeneous systems. In: Progress in Dielectrics (ed. J. Birks), Vol. 7, p. 69. London Heywood Books, Stamford St., London.

Correspondence: Dr R.G. Craig, University of Michigan, School of Dentistry, Ann Arbor, MI 48109-1078, U.S.A. 